\title{
Subsurface horizontal microfracture propagation within the middle member of the Bakken Formation, Williston basin, North Dakota: Evidence and implications
}

Travis Blackburn Warner

West Virginia University

Follow this and additional works at: https://researchrepository.wvu.edu/etd

\section{Recommended Citation}

Warner, Travis Blackburn, "Subsurface horizontal microfracture propagation within the middle member of the Bakken Formation, Williston basin, North Dakota: Evidence and implications" (2011). Graduate Theses, Dissertations, and Problem Reports. 3442.

https://researchrepository.wvu.edu/etd/3442

This Thesis is protected by copyright and/or related rights. It has been brought to you by the The Research Repository @ WVU with permission from the rights-holder(s). You are free to use this Thesis in any way that is permitted by the copyright and related rights legislation that applies to your use. For other uses you must obtain permission from the rights-holder(s) directly, unless additional rights are indicated by a Creative Commons license in the record and/ or on the work itself. This Thesis has been accepted for inclusion in WVU Graduate Theses, Dissertations, and Problem Reports collection by an authorized administrator of The Research Repository @ WVU. For more information, please contact researchrepository@mail.wvu.edu. 
Subsurface horizontal microfracture propagation within the middle member of the Bakken Formation, Williston basin, North Dakota: Evidence and implications

Travis Blackburn Warner

Thesis submitted to the

Eberly College of Arts \& Sciences

at West Virginia University

in partial fulfillment of the requirements

for the degree of

Master of Science

in

Geology

Richard Smosna, Ph.D., Chair

Kathy Bruner, Ph.D.

Helen Lang, Ph.D.

Department of Geology \& Geography

Morgantown, West Virginia

2011

Keywords: Bakken; Horizontal Microfracture

Copyright 2011. Travis Blackburn Warner 


\section{ABSTRACT \\ Subsurface horizontal microfracture propagation within the middle member of the Bakken Formation, Williston basin, North Dakota: Evidence and implications}

\section{Travis B. Warner}

The Devonian-Mississippian Bakken Formation of the Williston basin does not outcrop. All rock samples are obtained by coring. Open, uncemented, horizontal mode I (joints, with no sense of shear) microfractures (with apertures typically 5 to 25 microns) in the Bakken Formation's middle member have debated origins: natural or induced by coring. Samples were taken from two cores associated with the Williston basin's Nesson anticline, and horizontal microfractures were characterized, counted, and compared with geologic variables to determine what controls, if any, existed. Results support the theory that some Bakken middle member horizontal microfractures propagated naturally in the subsurface.

The majority of horizontal microfractures were clearly induced, exhibiting shear morphology. A minority of horizontal microfractures, all mode I joints with no sense of shear, were observed to have submicroporosity (less than 1 micron wide; effectively not resolvable with standard transmitted light optics) emanating approximately 150 microns above and below the microfracture apertures. Such horizontal microfractures with submicroporosity zones are termed HMFs in this study. Epifluorescence microscopy was necessary to visualize microporosity-associated submicroporosity. If secondary, submicroporosity would likely have required elevated temperatures, fluid flux, and geologic time to have generated. Coring alone is unlikely to have generated such submicroporosity; subsurface propagation of HMFs explains the observation better.

Three observations further suggested HMFs were propagated in situ. First, HMFs were found to be most abundant in dolostone lithology, and were rare or absent in calcite-dominated lithology. The association with dolomite suggested subsurface propagation because dolostone is more brittle than limestone only at subsurface temperature and pressure conditions. If HMFs had propagated as a result of coring, calcite and dolomite lithologies would have experienced similar microfracturing, and no disparity would have been observed. Second, HMFs were most abundant within a ten-foot proximity of a source-rock. The working hypothesis that in situ HMF propagation was driven by hydrocarbon generation and expulsion explains the source-rock proximity trend. Third, HMFs were most abundant where macroporosity (pores resolvable with standard transmitted light optics) was least. This either suggests the existence of macropores prevented microfracture propagation, or the minerals leached during HMF secondary submicroporosity development precipitated in, and closed, nearby macroporosity. No evidence was found to validate either explanation; however, the latter suggests in situ processes.

The Bakken was buried to the oil window in the Late Cretaceous. Also during the Late Cretaceous, the Nesson anticline underwent growth and uplift, evident from sediment isopach maps in the Williston basin; far-field horizontal stresses from the Laramide orogeny are thought to be responsible. A maximum horizontal stress regime concurrent with Bakken oil generation and expulsion could account for HMF propagation as their observed characteristics suggest; superlithostatic fluid pressures are not necessary to explain the propagation. 


\section{ACKNOWLEDGEMENTS}

Educators inspire, challenge, encourage, and make possible the achievements of their students. I would like to dedicate this thesis to the first three great educators I had: Gregory Dodd, William 'Doc' Crouch, and Gene Petri.

I owe many thanks to the geologists whose tutelage have turned my hobby into my profession: Brian Bierman, Peter Cooke, Daniel Kile, Richard Bisbing, Dr. Helen Lang, Dr. Dengliang Gao, Dr. Timothy Carr, Dr. Jaime Toro and Dr. Kathy Bruner. I am most grateful to my professor and advisor Dr. Richard Smosna, whose dynamic introductory geology lectures were the impetus of my becoming a geologist, and whose later courses have affected every aspect of my career. His input, constructive criticism and patience have made this thesis possible.

Others who assisted me greatly during this process include Julie LeFever of the North Dakota Geological Survey and Kathy Stolper of Stolper Geologic, Inc. who both provided valuable insight; my friend and colleague Johnathan Moore, whose discussions were unbelievably helpful; Greg Vardilos of TPS Enterprises who provided thin sections and petrographic advices, and Vivek Singh of the West Virginia University Physics Department who provided X-ray diffraction assistance.

This thesis would not have been possible without the financial support provided by Oak Ridge Institute of Science and Education in concert with the Department of Energy's National Energy Technology Laboratory in Morgantown, West Virginia. I also extend my gratitude to West Virginia University's Geology and Forensic and Investigative Science departments, as well as the North Dakota Geological Survey's core library which all provided the facilities necessary to complete this thesis.

Finally, I thank my friends and family who have supported me throughout this endeavor; most especially my wife Emily, who has made it all worthwhile. 


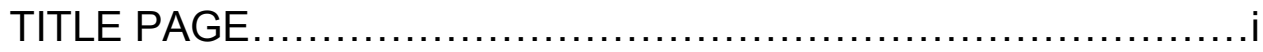

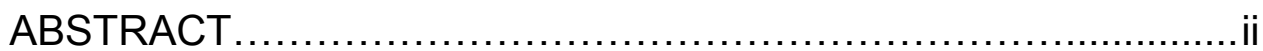

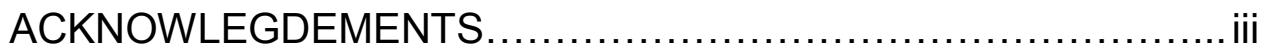

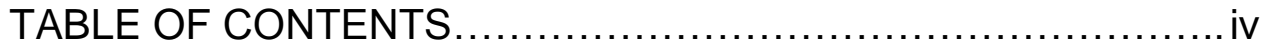

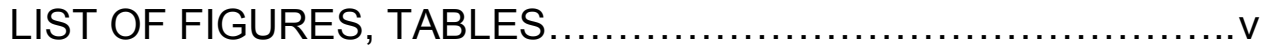

LIST OF THESIS-SPECIFIC TERMS ..............................

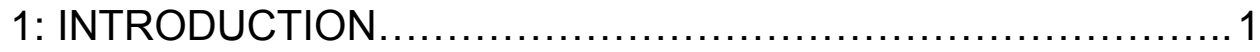

2: GEOLOGIC SETTING......................................... 13

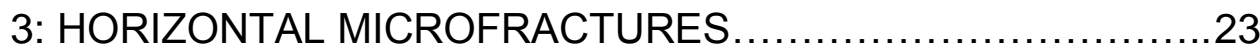

PREVIOUS WORK ......................................23

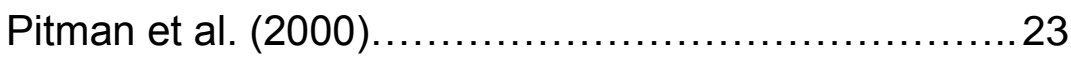

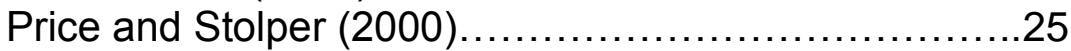

DISCUSSION.................................................. 29

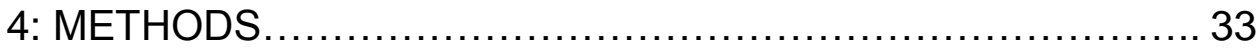

5: RESULTS AND DISCUSSION.................................. 39

HORIZONTAL MICROFRACTURE CHARACTERIZTION. 39

Submicroporosity development......................... 39

Induced fractures...................................... 41

HMF density calculation............................... 41

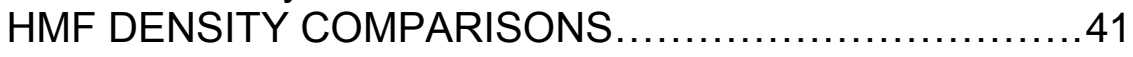

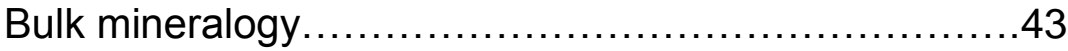

Macroporosity ........................................ 45

LeFever (2007) lithofacies............................ 47

Middle member thickness.............................48

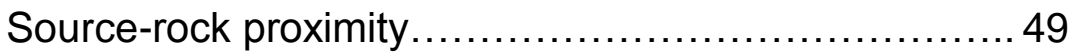

Source-rock thickness............................... 52

SUMMARY .............................................. 52

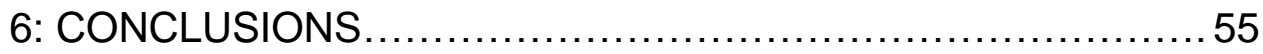

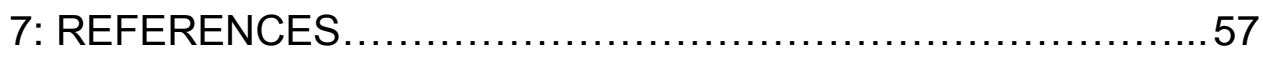




\section{LIST OF FIGURES}

1. Williston basin Devonian-Mississippian stratigraphy.................... 2

2. A) Horizontal microfractures in core; B) in thin section................... 4

3. A) Study well location map; B) Axis well; C) Flank well.................... 6

4. Bakken Formation structure map...................................... 8

5. Nesson anticline structure open- and closed-fluid hypothesis............. 9

6. Bakken Formation burial curve ...................................... 11

7. Bakken Formation paragenetic sequence............................. 14

8. A) Horizontal microfracture; B) Horizontal microfracture

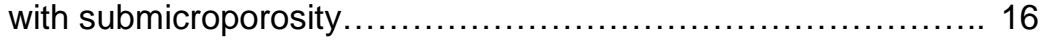

9. Horizontal microfracture network ..................................... 18

10. Dolomite vs. Source-Rock Proximity and HMF Density ...................20

11. HMF Density vs. Macroporosity ...................................... 22

12. Basement lineament map of Williston basin region...................... 24

13. Late Cretaceous sediment isopach map in Williston basin............... 26

14. A-E) Bakken sequence stratigraphic deposition model.................. 28

15. Lower Bakken member isopach map.................................. 30

16. LeFever (2007) Lithofacies descriptions .............................. 32

17. Middle Bakken member isopach map.................................. 34

18. Upper Bakken member isopach map................................ 35

19. Hydrolytic disproportionation of organic matter reaction pathway ....... 40

20. Bakken Formation lithofacies type log................................. 42

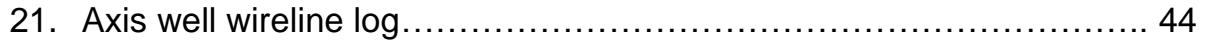

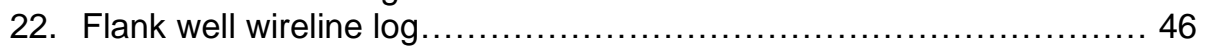

23. Induced fracture with en echelon morphology ......................... 48

24. Thermal maturity ( $\mathrm{T}_{\text {MAX }}$ and $\%$ Ro) map............................. 50

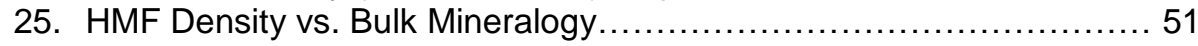

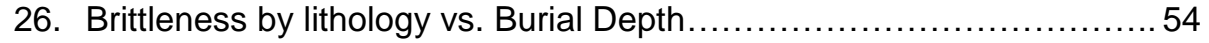

\section{LIST OF TABLES}

1. Middle member sample point-count data and calculations................37

2. Upper and lower member sample TOC data........................... 38 


\section{LIST OF THESIS-SPECIFIC TERMS}

HMF -

open, uncemented, horizontal microfracture which occurs in the Bakken middle member as a mode I joint with no sense of shear; has associated submicroporosity (less than 1 micron; effectively unresolvable with standard transmitted light optics) halo approximately 150 micrometers above and below the aperture; thought to be naturally occurring, in situ, at depth; thought to be hydraulically propagated during the Late Cretaceous as a result of far-field maximum horizontal stress and contemporaneous hydrocarbon production.

Macroporosity - matrix porosity (non-fracture porosity) which is effectively resolvable with standard transmitted light optics; greater than 1 micron wide

Submicroporosity - matrix porosity (non-fracture porosity) which is effectively unresolvable with standard transmitted light optics; less than 1 micron wide; exclusively associated with horizontal microfractures within a halo approximately 150 micrometers above and below the microfracture aperture; thought to be naturally-occurring as secondary porosity

Natural - $\quad$ (referring to microfracture propagation) occurring at depth, in the subsurface; in situ; not induced

Induced - $\quad$ (referring to microfracture propagation) occurring as a direct result of drilling, coring, core manipulation, core retrieval, core storage, or core desiccation; not natural

Lithofacies - $\quad$ chronostratigraphic intervals within the Bakken middle member defined by LeFever (2007), characterized by lithology; each includes its own set of depofacies and lithologies which vary geographically throughout the Williston basin; each can be distinguished in wireline logs and can be correlated throughout most the basin; in stratigraphic order - 1, 2, Central Basin Facies (CBF), 3, 4, and 5 


\section{1: INTRODUCTION}

The Devonian-Mississippian Bakken Formation of the Williston basin consists of

three informal members: the lower, middle, and upper members (Fig. 1). The lower and upper Bakken members are organic-rich black shales considered among the best petroleum source rocks in the world (Smith and Bustin, 2000). The shales are incredibly productive due to their abundance of hydrogen-rich, oil-prone, Type I and II kerogen. Immature Bakken shales reach 35\% by weight total organic carbon (TOC). The middle member is a complex unit consisting of siltstone, sandstone and carbonate. The entire Bakken Formation is bound above and below by tight, effectively impermeable limestones. In portions of the Williston basin where vertical fracturing is absent and the Bakken is buried to oil window depths, it is thought that a closed-fluid petroleum system exists within the Bakken Formation (Price, 2000).

Networks of open, uncemented horizontal mode I microfractures (joints with no sense of shear) are observed in the Bakken Formation's middle member (Fig. 2). Debate exists as to whether the horizontal microfractures are natural (i.e. in situ; propagated in the subsurface prior to coring) or induced during coring, core retrieval, or core storage. Proponents of natural horizontal microfractures within the Bakken concluded horizontal microfracture propagation was driven by oil generation in, and expulsion of oil from, the organic-rich shales of the Bakken upper and lower members into the middle member (Price, 2000; Price and Stolper, 2000; Pitman et al., 2001). Superlithostatic fluid pressures (greater than $1.0 \mathrm{psi} /$ foot) during rock failure are thought to be necessary to overcome the maximum vertical overburden stress. To achieve superlithostatic fluid pressures, a complex explanation involving closed-fluid Bakken 


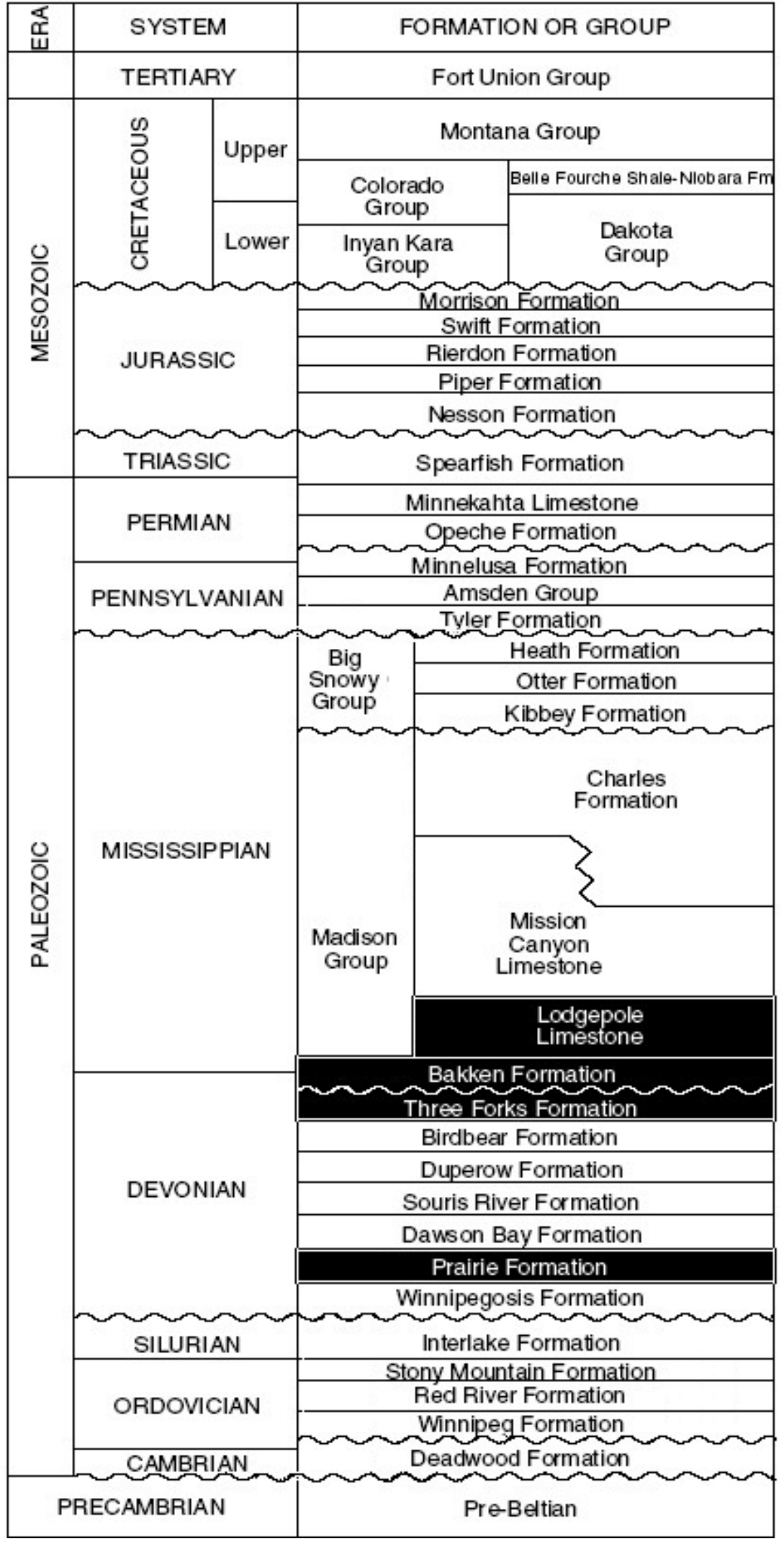

Figure 1: Williston basin stratigraphic column. The Bakken Formation and underlying and overlying limestone formations are highlighted in black. Also in black is the Devonian Prairie Formation evaporite. Dissolution may have caused collapse of overlying sediment resulting in local Bakken thickness variations. 
petroleum system dynamics (Price, 2000), chemical reactions creating excess methane and carbon dioxide (Price, 2000; Pitman et al., 2001), and kerogen compression and decompression (Price and Stolper, 2000) had been proposed. While a closed-fluid petroleum system is feasible in the Bakken Formation, the other theories are unproven and based on a flawed concept of the stress state at the time of Bakken horizontal microfracture propagation.

Opponents of natural horizontal microfractures posit the horizontal fractures are induced and are exfoliation joints and/or desiccation cracks (Jump 2009). As core is brought from the subsurface to the surface (the Bakken does not outcrop; all samples are core-derived), the decrease in confining pressure may have caused horizontal jointing to occur. As the core dries in storage, further horizontal jointing along planes of weakness, like along horizontal bedding planes, may have occurred (Jump, 2009).

Currently, porous sandstones and carbonates in the middle Bakken member are the targets of reservoir development by the petroleum industry. The middle member has characteristically low permeability and therefore requires horizontal drilling and hydraulic fracturing to be economic. Networks of open, uncemented horizontal microfractures, if naturally occurring in the subsurface, could be fracture-porosity oil reservoirs previously unrecognized by the petroleum industry. If natural, the horizontal microfractures could conceivably add to reserve estimates and/or broaden the expanse of the middle member Bakken play.

This thesis was originally conceived to explore the petrographic differences between open and closed-fluid petroleum systems in the Bakken Formation. A Bakken closed-fluid petroleum system was proposed by Price and LeFever (1994) who 

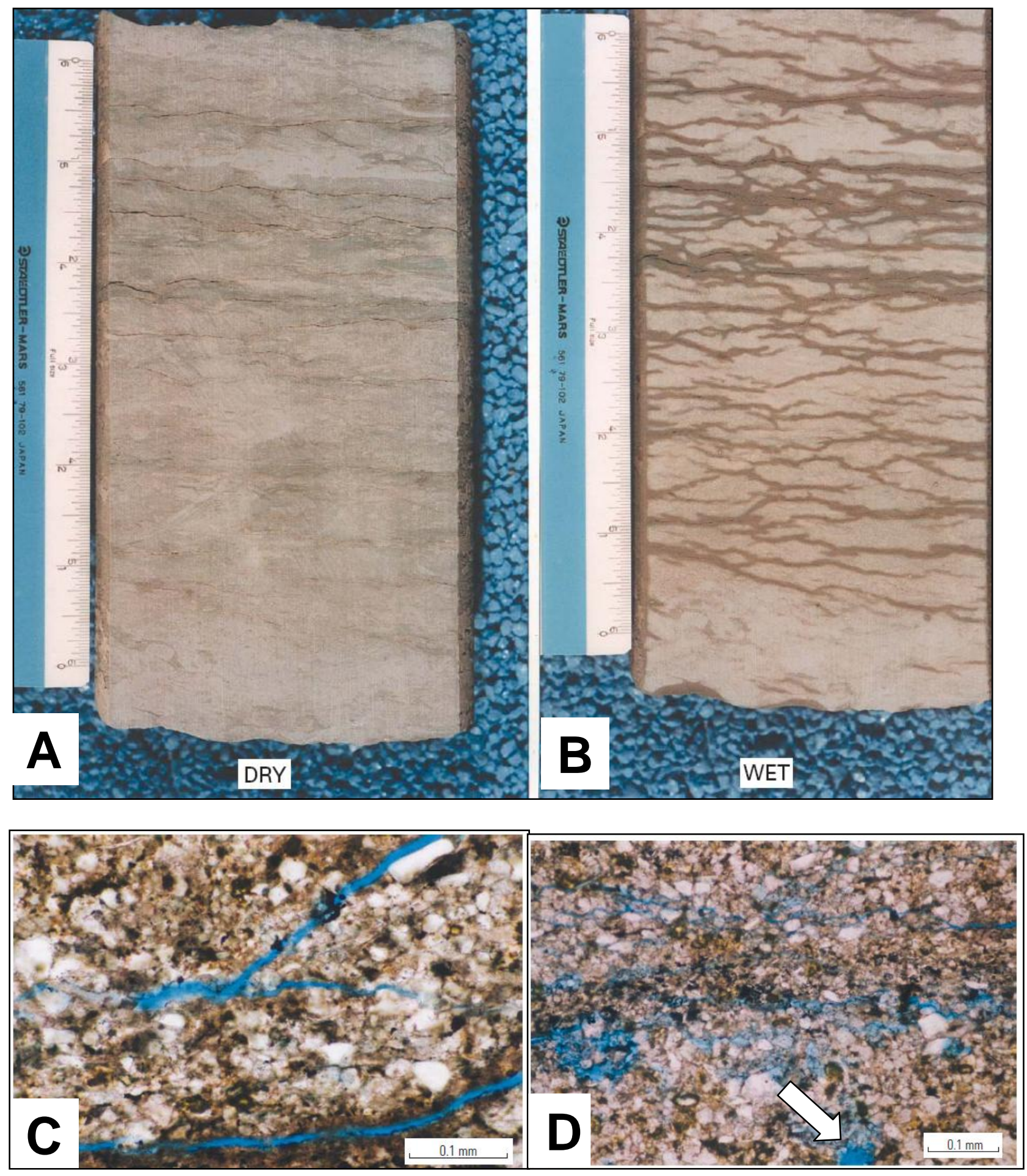

Figure 2: A) Dry and, B) wet slabbed core from the Bakken middle member, modified from Pitman et al. (2001). When wet, microfractures networks adsorb water and can be seen as dark horizontal networks. C) Photomicrograph illustrating horizontal microfracture porosity (blue lines). D) Photomicrograph illustrating secondary macroporosity (arrow) associated with horizontal microfracture porosity (blue lines). The porous and apparently permeable horizontal microfractures were presented as having the potential to be a fracture-porosity reservoir. Modified from Pitman et al. (2001). 
performed oil geochemistry analyses and concluded that Bakken-sourced oils are fundamentally different geochemically from oils outside the Bakken formation. This conclusion is reflected by the colloquial phrase, "what happened in the Bakken stayed in the Bakken" (Jump, 2009). After Price and LeFever (1994), other studies have supported the closed-fluid petroleum system model including Bachu and Hitchon (1996), Price (2000), Jarvie (2001), LeFever and Helms (2006), Chen et al., (2009), and Nordeng (2009). Other studies, like Williams (1974), Dow (1974), Meissner (1978), Osadetz et al. (1992), Meissner and Banks (2000), and Jiang \& Li (2002) found geochemical evidence of Bakken oils mixing with other oils throughout the basin, and therefore supported an open-fluid petroleum system. In a structurally-simple basin, I hypothesized that both Bakken open-fluid and closed-fluid petroleum systems could coexist spatially and/or temporally. In fact, I would argue that open and closed-fluid petroleum systems are the end-members of a continuous spectrum for petroleum system mechanics, albeit the latter is rare in currently economic hydrocarbon-producing basins (perhaps due to the familiarity of the former and failure to recognize the latter).

I chose two Bakken cores near the center of the Williston basin (Figs. 3A, 3B), with similar Bakken thermal maturities, to study hoping to recognize a closed-fluid Bakken petroleum system. The first core (NDGS \#15674 - the 'axis well') is located toward the center of the Williston basin (Fig. 3C) on the axis of the Nesson anticline, a prominent structure in the Williston basin (Fig. 4). The second core (NDGS \#17015 'flank well') is located six miles east of the axis well (Fig. 3D), on the flank of the anticline. 


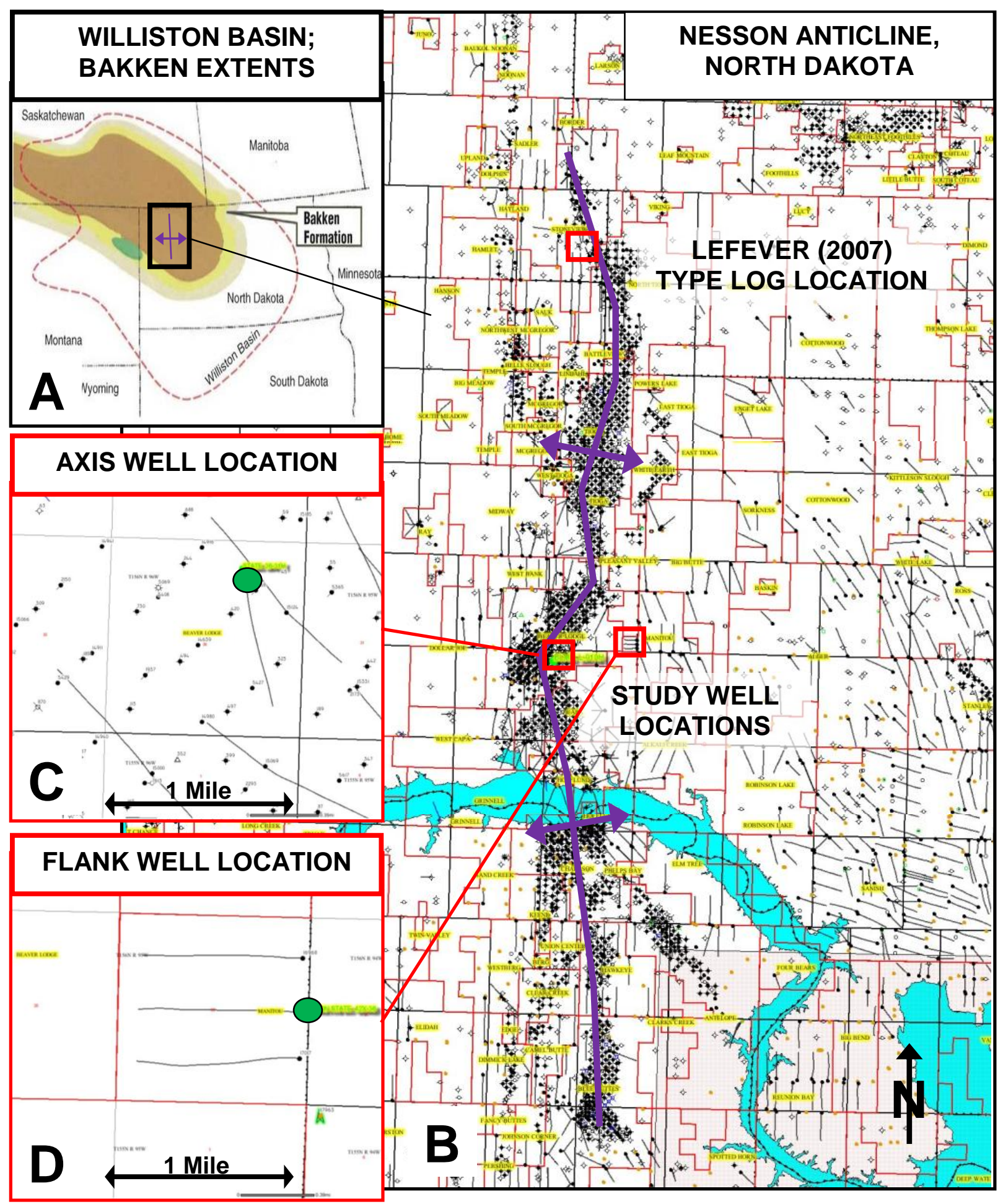

Figure 3: A) Map of Williston basin and Bakken Formation extents. The black box is enlarged to show B) the Nesson Anticline in North Dakota. The black dots represent well locations; the tadpoles represent horizontal wellbores. Note the density of well locations along the Nesson anticline axis (purple). Two red boxes near the center of the map are enlarged to show the study well locations (green) on $\mathbf{C}$ ) the anticline axis, and D) the anticline flank. The two wellbores are approximately 6 miles from one another. A third red box at the northern end of the anticline marks the location of the LeFever (2007) type log used to correlate this study's wireline logs. 
Originally, I hypothesized that the flank well would have experienced less bending than the anticline axis well. Therefore, the flank well would have less vertical fractures, and was more likely to be a closed-fluid petroleum system within the Bakken Formation, relative to the axis well (Fig. 5). Closed-fluid dynamics were largely responsible for the superlithostatic fluid pressures required for the propagation of horizontal microfractures observed in the middle member, according to Pitman et al. (2001) and Price (2000). One line of petrographic evidence supporting a closed-fluid petroleum system, I postulated, would be superlithostatic-natural horizontal microfractures. I hypothesized that if the flank well were more of a closed-fluid system than the axis well, then the flank would have a greater intensity of natural horizontal microfractures. Thus, I was faced with the problem of differentiating between natural and induced horizontal microfractures in thin section. I was also faced with justifying that these fractures could in fact be natural by reviewing the mechanisms proposed by in situ horizontal microfracture proponents.

Reviewing the literature I found no quantitative evidence supporting a natural horizontal microfracture mechanism. Qualitative evidence was limited to a core analysis study of Price and Stolper (2000), who concluded that a positive correlation existed between increased thermal maturity and increased horizontal microfracture intensity. Price and Stolper (2000) interpreted this as proof that hydrocarbon generation and expulsion was the driving force, and therefore horizontal microfractures were generated naturally in the subsurface. Hydrocarbon generation in the Bakken was at its maximum during the late Cretaceous (Fig. 6); therefore fractures must have propagated during the late Cretaceous (Fig. 7). Based on the conclusion that horizontal microfractures were 


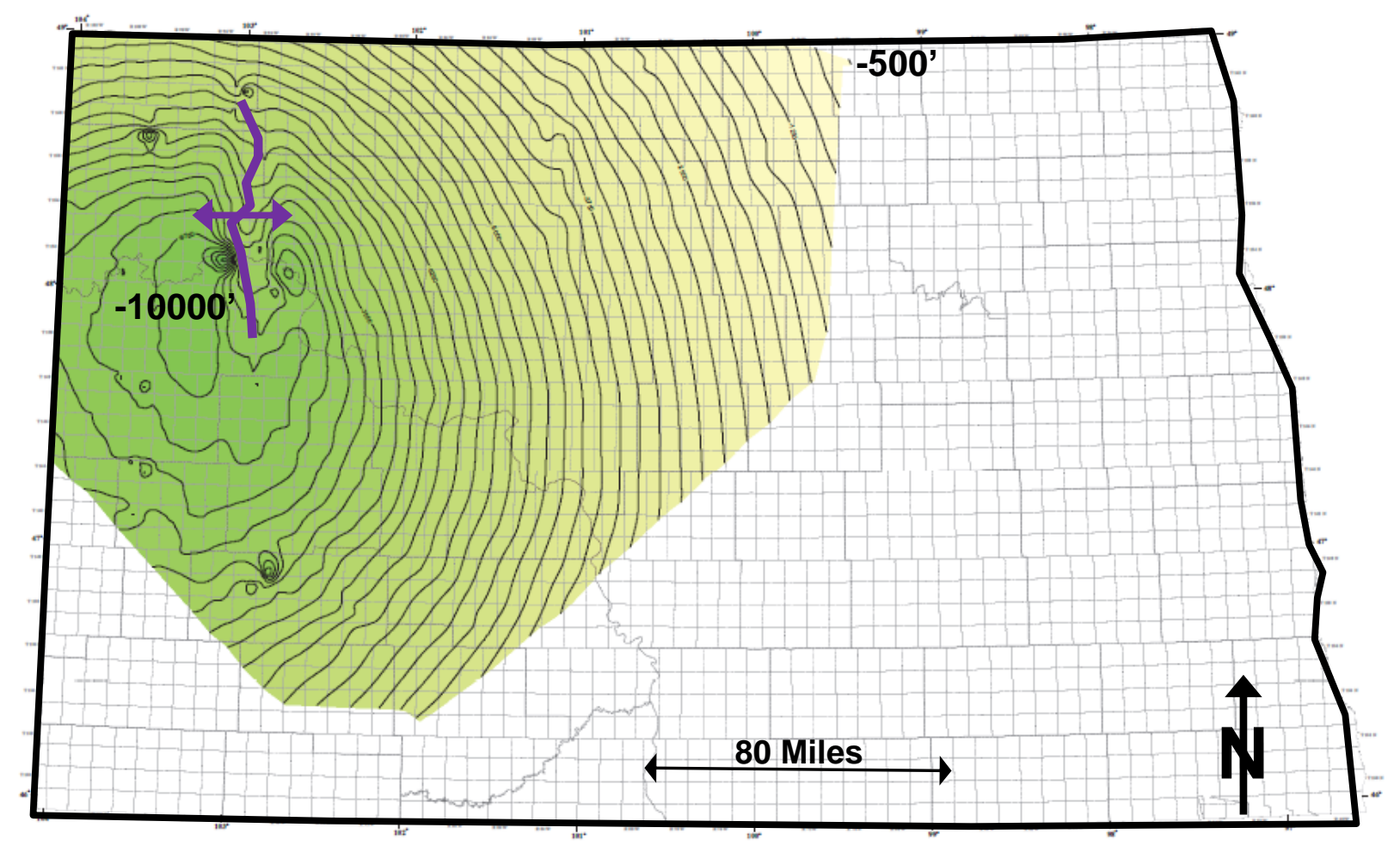

Figure 4: Top of Bakken Formation structure map in North Dakota, modified from LeFever (2008). Contours range from -500 to -10000 feet; the contour interval is 250 feet. The south-plunging Nesson anticline axis is marked in purple. The structural simplicity of the Bakken Formation in the Williston basin suggests ample area for a closed-fluid Bakken petroleum systems to persist. On the Nesson axis anticline, the structural complexity suggests an open-fluid Bakken petroleum system is more likely.

driven by oil production, Price and Stolper (2000) proposed that source-rock thermal maturity, thickness, and organic-richness were factors controlling microfracture development and intensity - as each increase hydrocarbon generation potential. I could find no further evidence that microfractures observed in core (Fig. 2B) and thin section (Fig. 2C, 2D) are indeed natural. Quantitative analyses supporting natural (or induced) in the Bakken middle member are lacking in my opinion. Additionally, there is no acknowledgement of potential changes in the stress regime through time, particularly the paleostress regime at the time of maximum Bakken hydrocarbon generation and expulsion. 


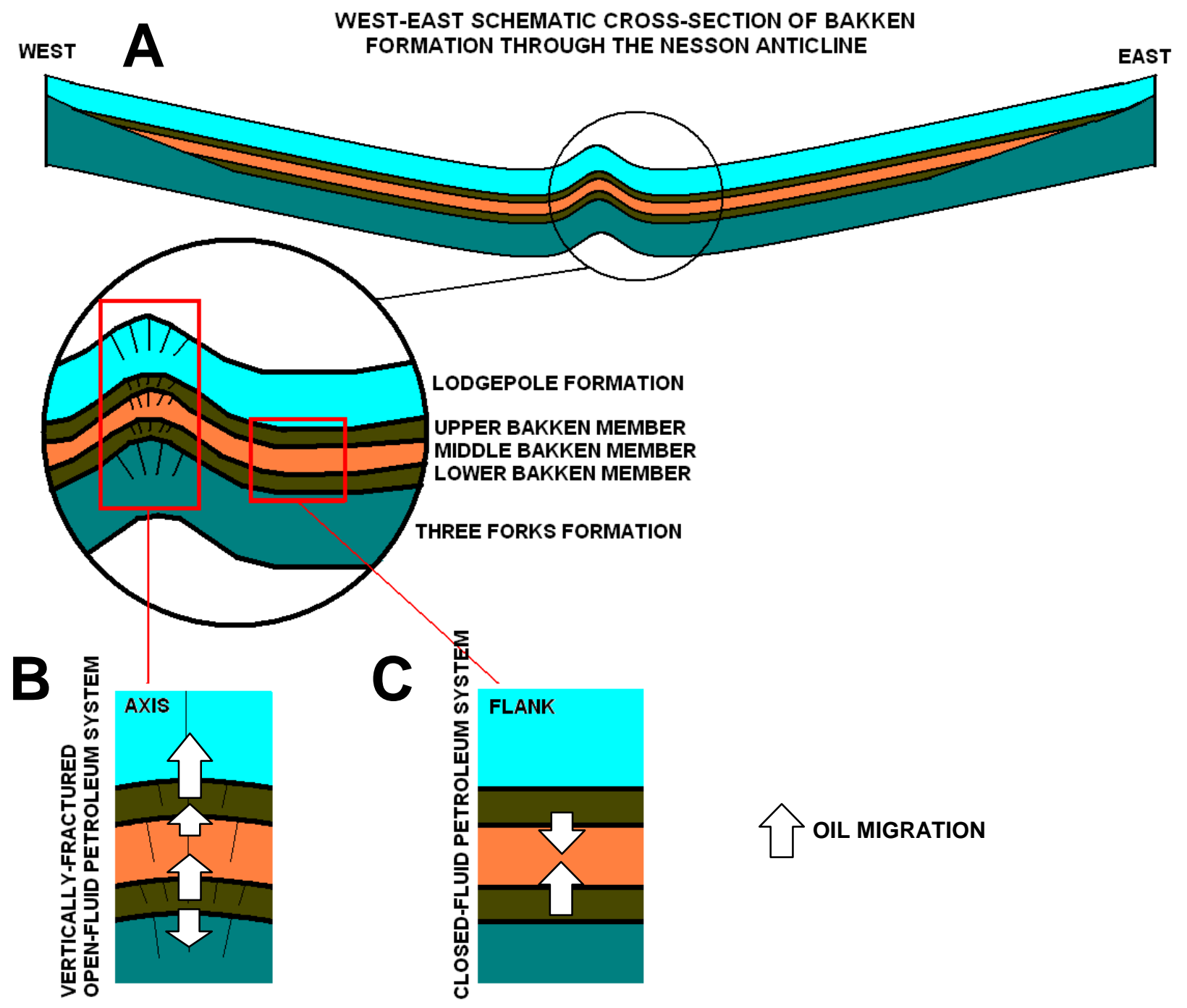

Figure 5: Schematic illustrations of my original hypothesis concerning the structural locations of openand closed-fluid Bakken petroleum systems (and consequent locations of horizontal microfractures). A) Schematic (not to scale) cross-section of the Bakken Formation and bounding Three Forks and Lodgepole limestones through the center of the Williston basin. The Nesson anticline is the only prominent structure. B) The Nesson anticline axis is more likely to have experienced vertical fractures associated with anticlinal bending. Vertical fractures provide oil migration pathways (arrows) out of the Bakken Formation; this system is described as an open-fluid petroleum system. C) The flank of the Nesson anticline is less likely to have experienced vertical fractures, and therefore oil migration from the Bakken source-rocks is more likely to have stayed within the Bakken Formation - a closed-fluid petroleum system. A closed-fluid petroleum system is likely to have higher fluid pressures than the open-fluid system. Horizontal microfractures (which require excessive fluid-pressures to propagate) are therefore more likely to occur in the closed-fluid petroleum system. 
This thesis is the culmination of my study of the Bakken middle member horizontal microfracture problem. I have identified four lines of qualitative and quantitative evidence that some horizontal microfractures in the middle Bakken were likely naturally propagated:

1) Submicroporosity (porosity less than 1 micron wide; effectively unresolvable with standard transmitted light optics) development above and below some horizontal microfractures (Figs. 8, 9) (fractures with such submicroporosity are termed HMFs throughout the thesis);

2) A positive correlation between HMF density (number of HMFs identified in a given thin section divided by the thin section's length) and dolomite (Table 1A; Fig. 10);

3) A positive correlation between HMF density and source-rock proximity (Table 1; Fig. 10);

4) A negative correlation between HMF density and macroporosity (non-fracture aperture porosity greater than 1 micron; resolvable with standard transmitted light optics) (Table 1; Fig. 11).

Points 1), 2) and 4) above are previously unrecognized in the literature on Bakken horizontal microfractures. Additionally, I identified an alternative mechanism to superlithostatic fluid pressure which accounts for the horizontality of the microfractures: contemporaneous Laramide orogeny far-field tectonic horizontal stresses within the Williston basin and maximum Bakken hydrocarbon generation. Marquez and Mountjoy (1996) noted a similar phenomenon in the Leduc Formation of the Alberta basin northwest of the Williston basin. 


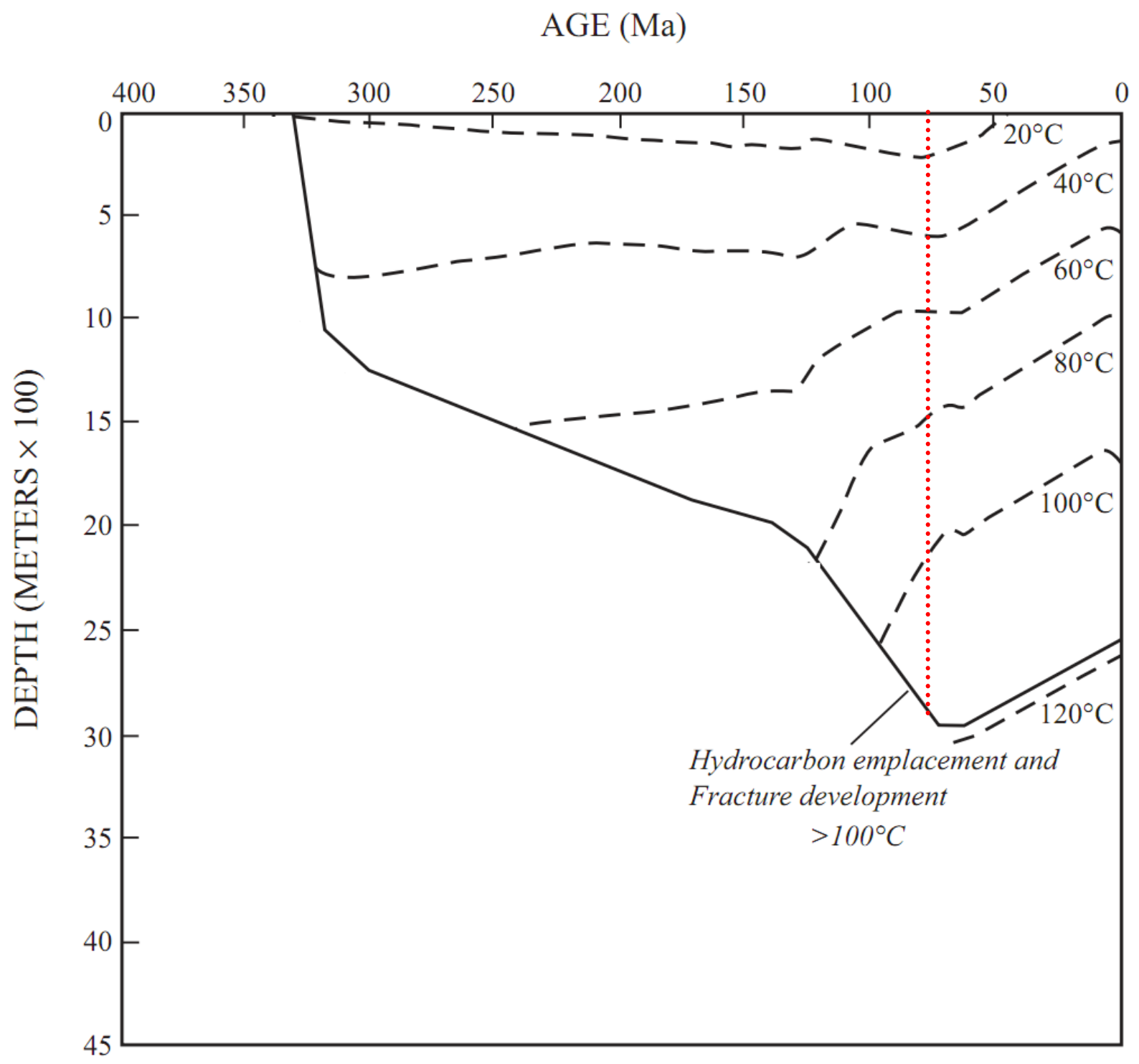

Figure 6: A Bakken Formation burial curve from the center of the Williston basin in North Dakota, modified from Pitman et al. (2001). The solid line represents the depth the Bakken Formation was buried through time. Dashed lines intersect the burial curve showing the depth and time the Bakken reached a given temperature. Pitman et al., (2001) interpreted hydrocarbon emplacement at temperatures greater than $100^{\circ} \mathrm{C}$. A dashed vertical line marks $75 \mathrm{Ma}$, when the Bakken Formation reached maximum burial depth, and likely maximum Bakken shale source-rock hydrocarbon production and expulsion. At the same time, late Cretaceous Laramide orogeny far-field tectonism is thought to have caused Nesson anticline deformation and uplift (Thomas, 1974). Contemporaneous maximum hydrocarbon generation and maximum horizontal stress in the Williston basin subsurface may have created conditions ideal for horizontal microfracture propagation within the middle Bakken member. 
I was not able to differentiate present day petroleum-fluid system dynamics as I had originally proposed, however I was able to add qualitative and quantitative data to the debate on natural versus induced horizontal microfractures within the Bakken middle member. 


\section{2: GEOLOGIC SETTING}

The Devonian-Mississippian Bakken Formation is part of the Williston basin. The basin spans the western two-thirds of North Dakota and portions of Montana, Saskatchewan, and Manitoba (Fig. 4). The deepest portions of the basin are located in North Dakota. The basin originated as a craton-margin basin, and evolved into an intracratonic basin during the Cordilleran orogeny (Gerhard et al., 1990). Based on the relative thickness of sediments, subsidence occurred most rapidly during the Ordovician, Silurian, and Devonian. Subsidence slowed in the Mississippian and ended in the Pennsylvanian before renewing, though much more slowly, in the Mesozoic (Thomas, 1974). The late Cretaceous Laramide orogeny was the last event to cause any significant tectonic structural activity within the basin (Fig. 6), notably growth of the Nesson anticline (Pitman et al., 2001; Heck et al., 2004; Flannery and Krauss, 2006).

The Nesson anticline is a prominent structure in the otherwise structurally-simple North Dakota portion of the basin (Figs. 4). The north-south trending Nesson anticline plunges southward through the center of the basin. Most of the oil produced in the basin is associated with this structure, as evident by the density of wells drilled along the feature (Fig. 3B). Recent advances in horizontal drilling and hydraulic fractures have broadened the viability of the Bakken play beyond the Nesson anticline axis. The cores studied in this thesis were located on the axis and flank of the Nesson anticline

(Fig. 3C, 3D). Vertical extension fractures are found in proximity to anticlines like the Nesson (Pitman et al., 2001), and led me to initially hypothesize that the axis well in my study would be more likely an open-fluid petroleum system relative the flank well (Fig. $5 B)$. 


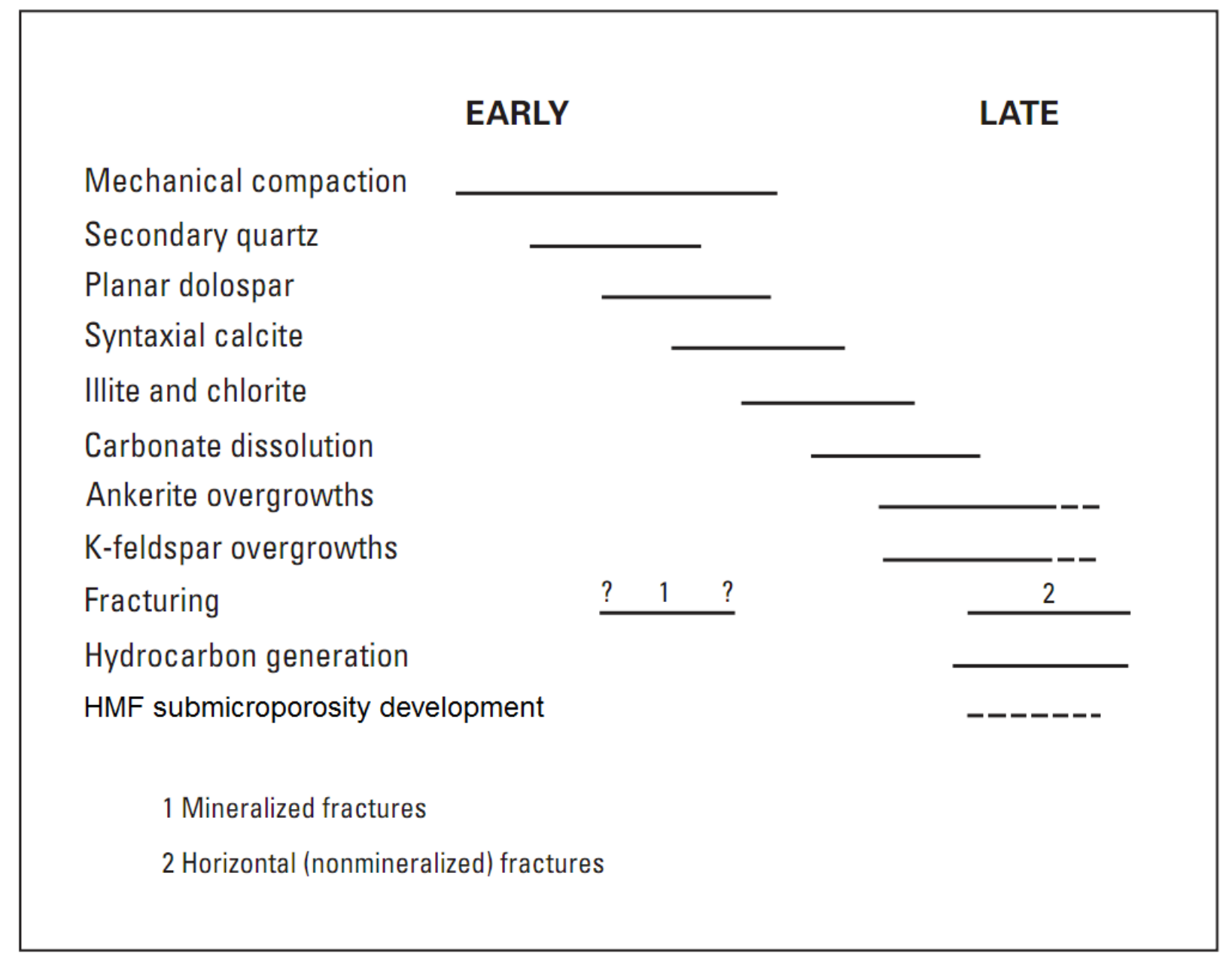

Figure 7: A Bakken Formation paragenetic sequence in North Dakota, modified from Pitman et al. (2001). Two phases of fracturing are interpreted by Pitman et al (2001). Mineralized fractures are thought to have propagated and cemented prior to hydrocarbon generation. Nonmineralized horizontal microfractures are interpreted to be caused by hydrocarbon generation. This study suggests (in dashed lines) secondary submicroporosity formed just after fracture propagation. The dissolved minerals may have precipitated elsewhere, filling macroporosity. This interpretation may possibly explain the Pitman et al. (2001) ankerite and K-feldspar overgrowths occurring during hydrocarbon generation and horizontal fracturing. This study suggests such mineral precipitation likely occurred as long as submicroporosity was created (dashed lines extending ankerite and K-feldspar overgrowth).

The Nesson anticline underwent periodic deformation throughout the history of the Williston basin. The most recent reactivation of the Nesson anticline occurred in association with far-field Laramide tectonism during the late Cretaceous. Right-lateral adjustment of the underlying Weldon basement block and subsequent compressive buckling is credited as the structural mechanism for fault activation on the west margin of the Nesson anticline (Thomas, 1974) (Fig. 12). Isopach maps of late Cretaceous 
sediment show thinning of sediment over the anticline axis, which supports the idea of Nesson anticline uplift during that time (Flannery \& Krauss, 2006) (Fig. 13). The growth of such features like the Nesson anticline in the region suggests the maximum stress regime was likely oriented horizontally during the late Cretaceous (Marquez and Mountjoy, 1996).

The Bakken Formation consists of two organic-rich black shales with a siltstonesandstone-carbonate member between them (Fig. 1). The Bakken is confined to the subsurface and does not outcrop (Fig. 4). All three members are continuous throughout the Williston basin, except toward the edges of the basin where they thin depositionally or erosionally to zero thickness. A maximum thickness of the Bakken Formation reaches 160 feet in the center of the basin on the flanks of the Nesson anticline (LeFever et al., 1991) (Fig. 4). Local variations in Bakken Formation thickness are thought to be controlled by pre-existing basement faulting (LeFever et al., 1987), partial dissolution of Middle Devonian Prairie Formation evaporatites and subsequent collapse of overlying formations (Green et al., 1985), erosion of the underlying Three Forks Formation during the Late Devonian lowstand systems tract (Smith and Bustin , 1995), and uplift of the Nesson anticline during Bakken deposition (LeFever, 2007). All these controls were capable of locally increasing accommodation space for Bakken sedimentation, and thus increasing Bakken Formation thickness.

In the Late Devonian, prior to deposition of the Bakken, the Williston basin was located near the equator in the center of the North American craton. Most of the western North America was covered by an epeiric sea (Gerhard \& Anderson, 1988; 


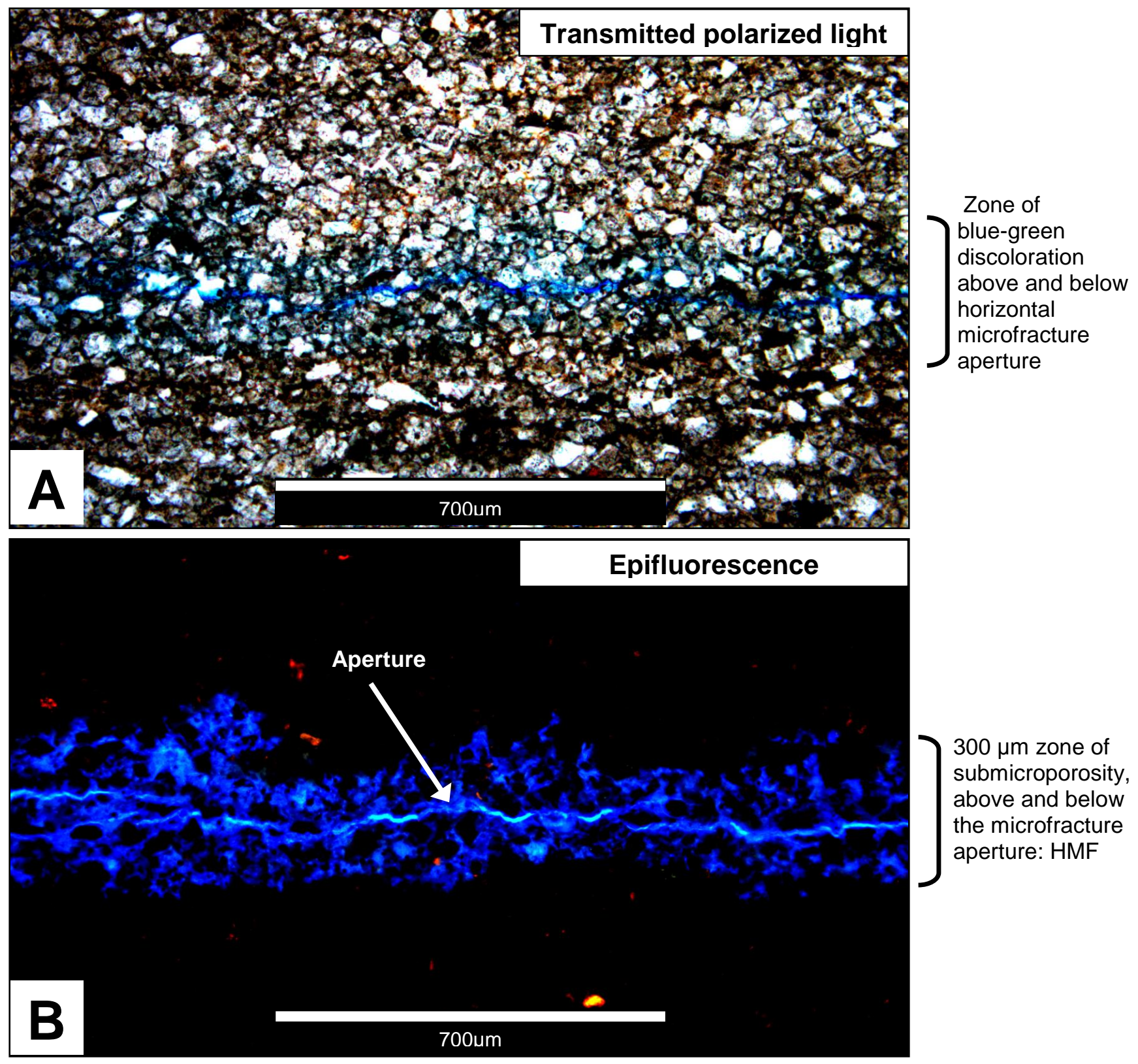

Figure 8: A) A photomicrograph of horizontal microfracture with a blue-green halo. Transmitted white light was not adequate to photograph the zone of discoloration, so epifluorescence was used to assist imaging. The photomicrograph is from sample 10319.00', which is a laminated silty dolostone with a HMF density of $5.1 \mathrm{HMFs} / \mathrm{cm}$ and has rare macroporosity. The blue epoxy injected into the pores is spiked with fluorochromes. Under wide-band UV reflected light, the epoxy fluoresces a bright blue. The same view is shown in B) imaged only with epifluorescence, reveals all porosity filled with epoxy in bright blue. A zone of submicroporosity emanates approximately 150 micrometers above and below, and subparallel to, the horizontal microfracture aperture. The red grains are crystals which reflect UV light.

The development of submicroporosity is unlikely to occur during induced fracturing, suggesting an in situ, at depth origin for both the microfracture and its associated submicroporosity. Horizontal microfractures with submicroporosity halos are termed "HMFs" in this study. 
Richards, 1989). The Late Devonian Three Forks Formation, a thinly bedded, tan to apple-green, muddy to finely crystalline dolostone, siltstone, and fine-grained sandstone, was deposited in this tropical shallow-marine to supratidal environment (Dumonceaux, 1984).

Active orogens - Antler to the west, Acadian to the east, and Ellesmere (Innuitian) to the north - surrounded the North American interior on three sides during the Late Devonian. Compressive stresses translated laterally though the North American craton and caused periodic base-level changes in the interior (Beaumont et al., 1987). Basement block-fault movements in the Williston basin and adjustments (mostly uplift) of the Severn arch, Wisconsin arch, Transcontinental arch, and Central Montana uplift caused relative sea-level fluctuations throughout the late Devonian and early Mississippian (Smith, 1986; Gerhard \& Anderson, 1988; Richards, 1989; Smith and Bustin, 2000). A relative sea-level drop exposed the Three Forks Formation. The Sanish Sand member of the Three Forks Formation was deposited locally, where older Three Forks members had been eroded, in a lowstand beach or nearshore-marine environment (Dumonceauex, 1984; LeFever et al., 1991).

During the following transgressive systems tract, black shale of the lower Bakken member was deposited unconformably on top of the Three Forks in an offshore -marine environment with a stratified water column (Smith and Bustin, 2000) (Fig. 14A). The most commonly accepted depositional environment for the Bakken shales is a restricted marine environment with stratified anoxic bottom-waters capable of preserving organic matter generated from planktonic blooms (Nordeng, 2009). Such an environment may have been commonplace in equatorial basins starved of siliciclastic sediment due to 


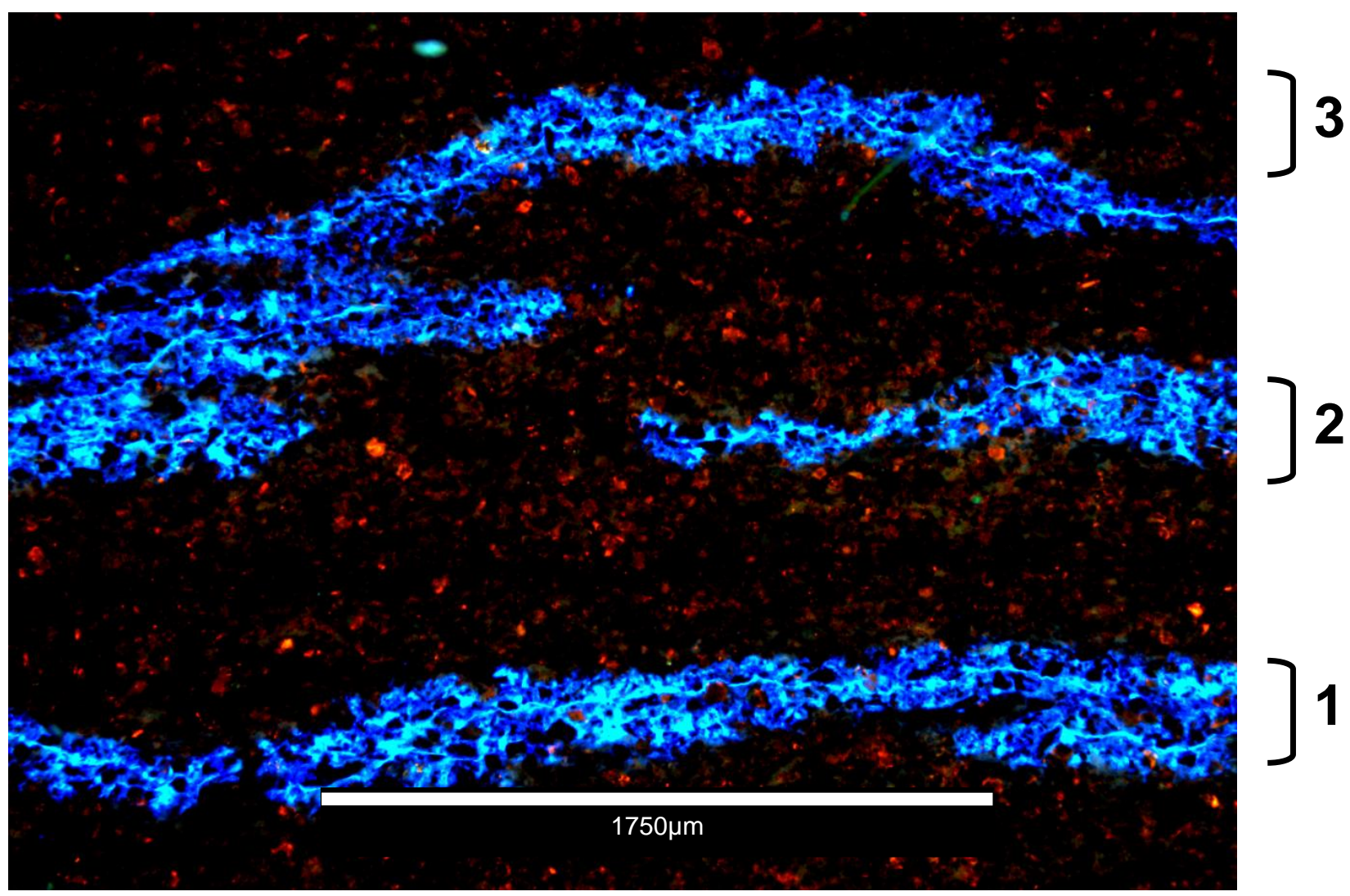

Figure 9: Epifluorescent photomicrograph of flank well thin-section from 10319.00' depth. 10319.00' is a laminated silty dolostone, and has a HMF density of $5.1 \mathrm{HMFs} / \mathrm{cm}$, with rare macroporosity. Fluorescentspiked epoxy injected into pore spaces reveals HMF apertures as bright blue subhorizontal lines and HMF submicroporosity zones as interconnected bright blue splotches emanating approximately 150 micrometers above and below, and subparallel to, the HMF apertures. The red grains are crystals which reflect UV light. This photomicrograph illustrates how HMFs often bifurcate, anastomize, or are discontinuous across a sample. I counted each discrete horizontal layer dominated by an HMF as one HMF. In this view, for example, I count three discrete horizontal layers (numbers and brackets on right); note the even vertical spacing. Note the lack of macroporosity, which would appear as individual bright blue points, in the matrix between HMFs.

stress. Vertical fracturing would decrease fluid pressures to below lithostatic transgressions too rapid for progradation to keep pace. The lower Bakken member is a dark-gray to brownish black, slightly to highly organic-rich shale. Pitman et al (2001) gives an adequate description of its lithology in North Dakota. Notably, the organic matter present in the lower member is derived from Type I and II. These kerogen types are typified as being hydrogen-rich and oxygen-poor relative to carbon, and therefore oil-prone upon thermal maturation. Total organic carbon (TOC), a measure of organic- 
richness, averages $8 \%$ by weight in the lower member, with a maximum concentration of $20 \%$ by weight where thermally immature (Smith and Bustin, 1996). TOC tends to decrease with increased thermal maturation as carbon is converted from kerogen to mobile hydrocarbons which migrate from the shales. The lower member reaches a maximum thickness of 56 feet at its depocenter east of the Nesson anticline (Fig. 15) (LeFever, 2008).

A rapid regression followed, depositing the middle Bakken member (Figs. 14B, 14C, 14D) on top the lower shale. The middle Bakken member consists of several lithofacies of high and low energy deposited in a shoreline environment (LeFever et al., 1991). It has a highly variable lithology consisting of interbedded sequences of siltstone, sandstone, and to a lesser extent shale, dolostone, and limestone rich in oolites and quartz silt and sand (Pitman et al., 2001; Ferdous, 2001). Numerous middle member stratigraphic classifications exist. LeFever's (2007) lithofacies descriptions are used in this thesis for comparison with middle member lithology observations in this thesis (Fig. 16) because LeFever's (2007) descriptions are recent, detailed, and derived from samples in the North Dakota portion of the Williston basin where my study cores are located. LeFever's (2007) 'lithofacies' are actually six chronostratigraphic intervals; each chronostratigraphic interval has several depofacies, and vary by lithology. Depofacies changes in the middle Bakken member suggest movement of the Nesson anticline during Bakken deposition (LeFever, 2007). The middle member reaches a maximum thickness of 90 feet in the basin center just east of 


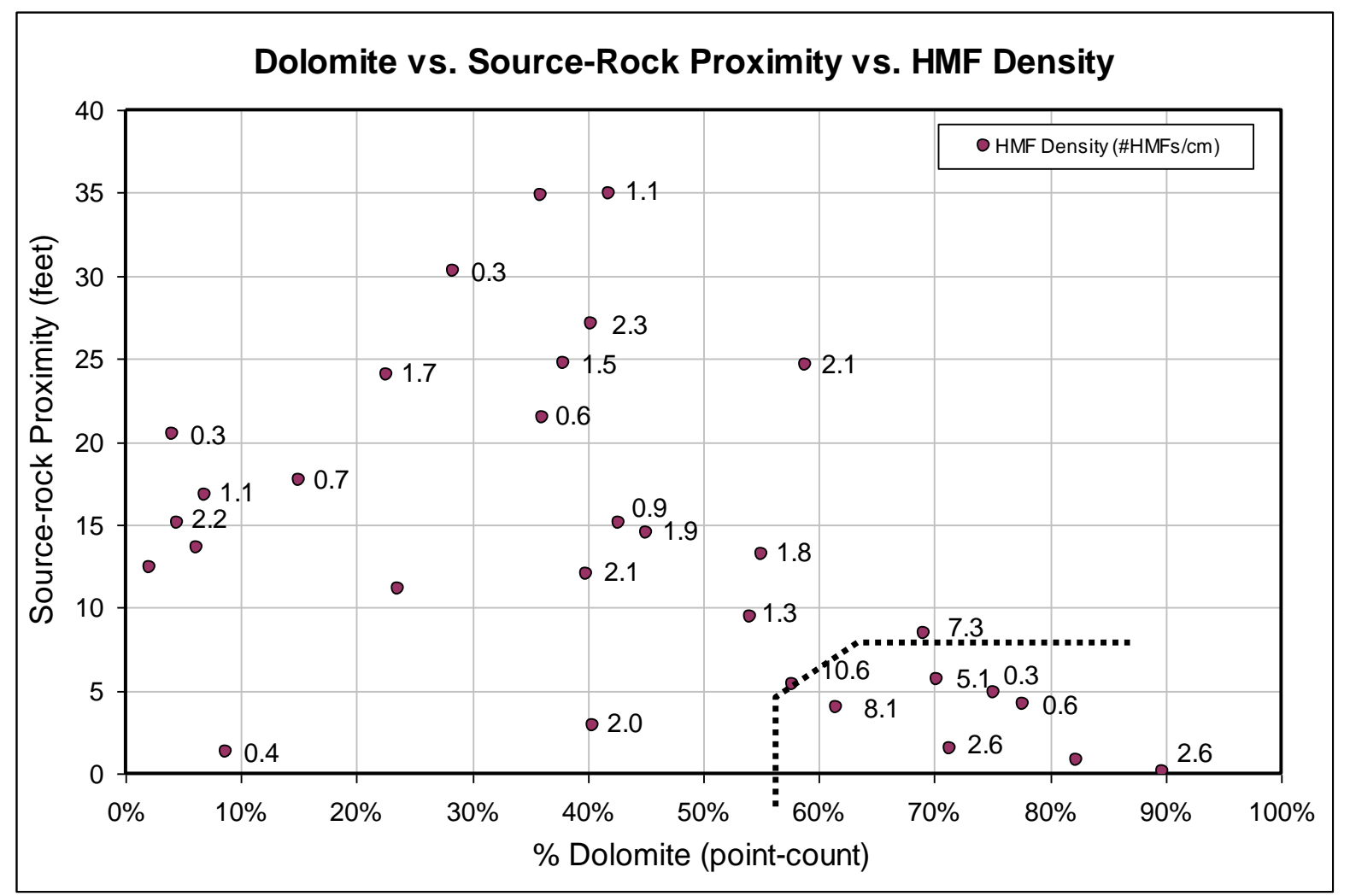

Figure 10: Plot of Bakken middle member percent dolomite versus source-rock proximity. Each point represents one sample, and is labeled with the HMF density where the sample's HMF density did not equal zero. The axis and flank wells are each represented. Percent dolomite was calculated from mineralogical point-count data; source-rock proximity is the distance in feet from the sample to the nearest organic-rich shale (either the upper or lower Bakken member contact). HMF density is the vertical density of submicroporosity-zoned horizontal microfractures for each sample. The dotted line demarcates samples with relatively high HMF density (greater than $2.6 \mathrm{HMFs} / \mathrm{cm}$ ) as dolomitic (greater than 55\%), and within 10 feet of an organic-rich shale. Samples with dolomitic lithology and source-rock proximity which do not have high HMF densities are within 5 feet proximity, and are dolomitic mudstones. It is possible these zones once hosted HMFs, but have since been cemented.

the Nesson anticline (LeFever, 2008) (Fig. 17). The middle member is the primary Bakken reservoir of oil, hosted by macroporosity in the sandier Central Basin Facies and oolitic Lithofacies 3 (LeFever, 2007). Oil is also posited to be present in natural microfractures (Price, 2000; Pitman et al., 2001) - the in situ nature of such microfractures are the subject of this thesis.

A second transgressive system tract occurred, causing deposition of the upper member on top the middle member, in an environment similar to that of the lower 
member (Fig. 14E). The upper member is therefore lithologically similar to the lower, being a dark-gray to brownish-black to black, fissile, slightly calcareous, organic-rich shale (LeFever et al., 1991). The upper member also has a higher organic content; it averages $10 \%$ TOC but may be as high as $35 \%$ TOC by weight where thermally immature (Smith and Bustin, 1996). The upper member reaches a maximum of 23 feet in North Dakota, but the depocenter is not easily defined (LeFever et al., 2008) (Fig. 18). Smith and Bustin (2000) noted that each Bakken member onlaps and exceeds the aerial extent of the underlying strata. As a highstand was reached, the upper Bakken member was overlain and overlapped by the prograding carbonate muds of the Devonian Lodgepole Formation (Smith and Bustin, 2000).

Diagenesis and paragenetic sequences for the middle Bakken member are well documented in North Dakota (Pitman et al., 2001) (Fig. 7) and in Saskatchewan (Ferdous, 2001). Notably, Pitman et al. (2001) identifies horizontal non-mineralized fractures occurring immediately after the beginning of hydrocarbon generation in the upper and lower members, reflecting the Pitman et al. (2001) conclusion that horizontal microfractures were driven by hydrocarbon generation and expulsion. The horizontal microfractures cease all water-based diagenetic changes by introducing oil to the middle member, according to the Pitman et al. (2001) model.

The Bakken Formation was buried to its maximum depths and to oil window thermal maturity in the center of the basin, during the late Cretaceous (Pitman et al., 2001) (Fig. 6). As discussed previously, Laramide orogeny far-field tectonism likely generated horizontal stresses within the Williston basin concurrent with the Bakken entering the oil window. 


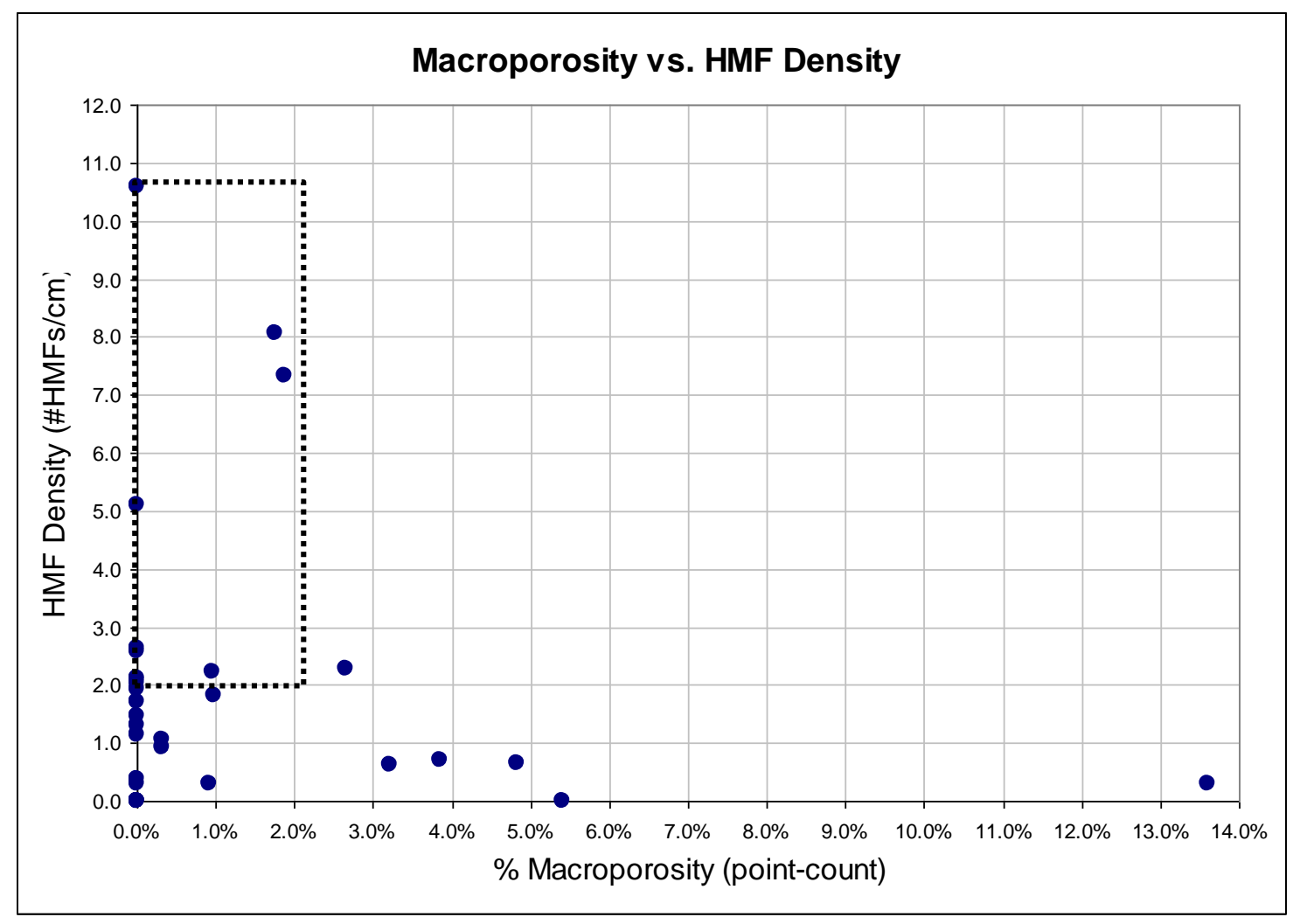

Figure 11: Plot of Bakken middle member percent macroporosity versus HMF density. Each point represents one sample. The axis and flank wells are each represented. Percent macroporosity was calculated from mineralogical point-count data (macroporosity is defined in this study as porosity resolvable by standard transmitted light optics). HMF density is the vertical density of submicroporosityzoned horizontal microfractures for each sample. The dotted line demarcates samples with relatively high $\mathrm{HMF}$ density (greater than 2.6 HMFs/cm) and relatively low macroporosity (less than $2.0 \%$ ). Samples with relatively high macroporosity (greater than 3.0\%) have relatively low HMF density (less than 1.0 HMFs/cm). Two hypotheses are posited based on the relationship observed in this plot: 1) macroporosity prevents microfracture propagation, or 2) macropores were cemented after horizontal microfracture propagation as a result of precipitation of minerals leached by near-microfracture submicroporosity development. 


\section{3: HORIZONTAL MICROFRACTURES}

Open uncemented horizontal microfractures have been described within the middle Bakken member and interpreted as naturally-occurring (Pitman et al., 2001; Price and Stolper, 2000). These middle member "porous and permeable horizontal microfractures serve to focus hydrocarbon fluids and locally enhance the quality of oil reservoirs at depth." (Pitman et al., 2001). Stated differently, "the oil generated by the Bakken shales would be principally stored in, and transmitted by, the fracture network[s]..." (Price and Stolper, 2000).

\section{PREVIOUS WORK}

\section{Pitman et al. (2000)}

Pitman et al. (2000) identified open uncemented horizontal microfractures in core by wetting slabbed core. As the core surfaces dried, open horizontal microfractures adsorbed water longer than unfractured portions of the core, highlighting the darkened microfracture networks (Fig.). Pitman et al. (2001) performed petrographic analysis on these microfracture networks and concluded they were mode I joints, i.e. fractures which opened perpendicular to the crack surfaces with zero shear stress (Figs. X, Y). Secondary macroporosity (porosity greater than 1 micron, resolvable with standard transmitted light optics) was identified near many horizontal microfractures (Fig.). Pitman et al. (2001) concluded that open uncemented horizontal microfractures were naturally-occurring, i.e. in situ; propagated in the subsurface. The Pitman et al. (2001) mechanism which drove horizontal microfracture propagation and generated secondary macroporosity in the middle member involved: 


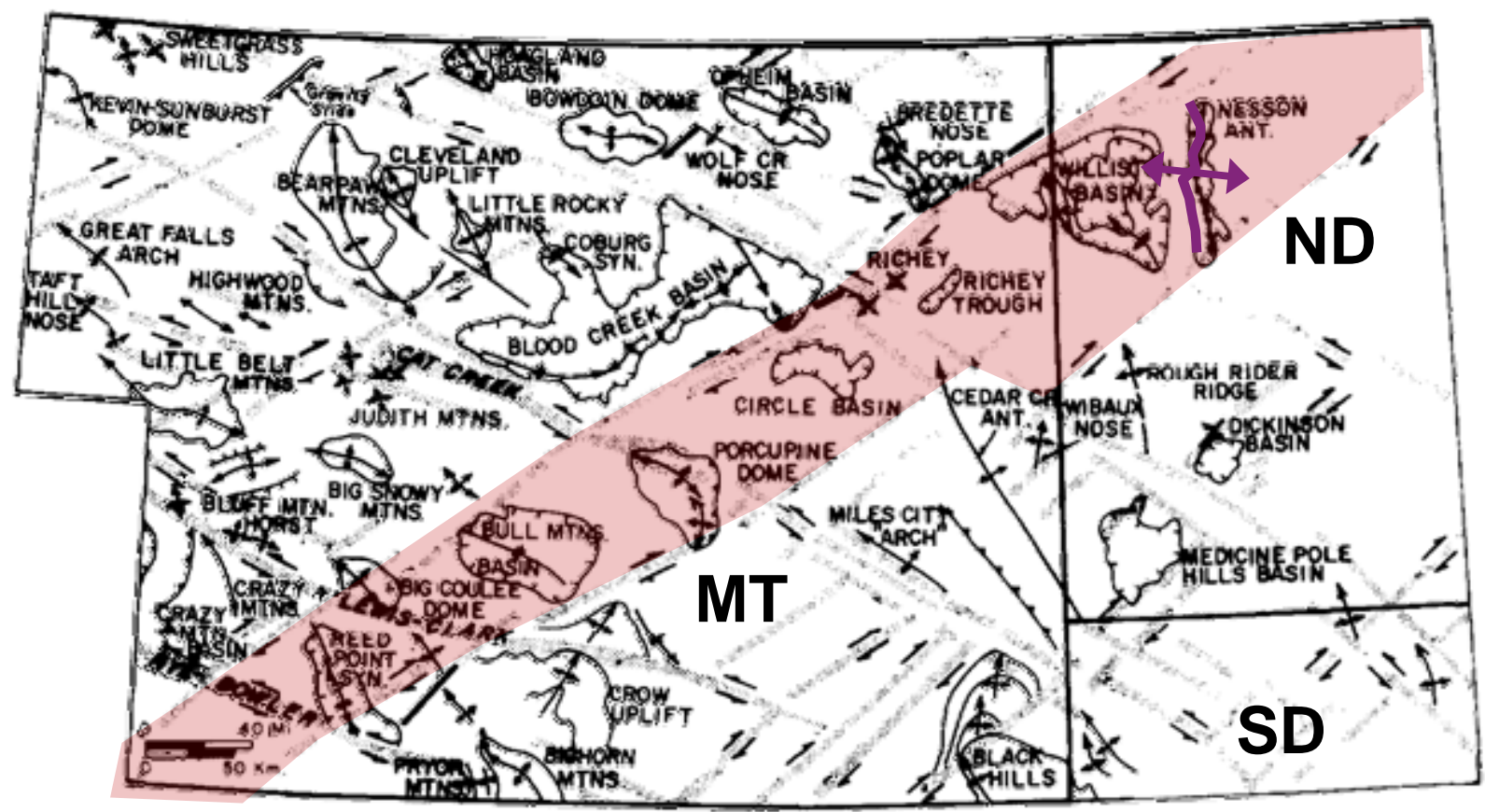

Figure 12: Structural features of US portion of the Williston basin area through eastern Montana (MT), western North Dakota (ND), and northwestern South Dakota (SD) overlain on basement lineamentdefined block framework, modified from Thomas (1974). Conjugate arrow sets mark lateral basement block adjustment patterns during Laramide orogeny far-field tectonism. The Weldon block (Thomas, 1974), shaded red, was posited to have experienced right-lateral adjustment during the Laramide orogeny - a process responsible for drag-folding deformation of the Nesson anticline (top right; purple).

Deformation and uplift of the Nesson anticline indicates a compressive stress regime in the Williston basin during the late Cretaceous.

1) hydrolytic disproportionation of organic matter (Price et al., 1998) - a reaction

between organic matter and water which is theoretically capable of breaking down kerogen to generate shorter-chained hydrocarbons, large volumes of carbon dioxide, methane, organic acids, and hydrogen (Seewald, 2003) (Fig. $19)$;

2) effectively impermeable limestones above and below the Bakken Formation which acted a pressure seals bounding the Bakken;

3) organic-rich, thick, and thermally mature upper and lower Bakken shales.

The Pitman et al. (2001) model is as follows. Hydrolytic disproportionation of organic matter (HDOM) is credited to have generated large amounts of carbon dioxide 
prior to thermogenic oil generation. The early-generated carbon dioxide drove expulsion of bitumen form the upper and lower shales into the middle member. HDOM continued, presumably, through thermogenic oil generation, at which point both processes synchronously generated large volumes of hydrocarbons. The kerogen catagenic reactions generated oil and gas products $150 \%$ the volume of the original kerogen reactants (Meissner, 1978; Price, 2000). Where the Bakken shale members were sufficiently organic-rich, thick, and thermally mature, large volumes of oil and gas were generated. The resultant fluid pressures within the Bakken were able to build to superlithostatic pressures because the Bakken was trapped between the effectively impermeable Three Forks and Lodgepole limestones. When mechanical rock failure did occur, it was because fluid pressures overcame the vertically-oriented maximum stress. Fractures propagated horizontally. The fluids driving propagation were organically-acidic oils. These oils filled the horizontal fractures upon inception and ceased water-based diagenetic reactions. The organic acids in the oil leached some of carbonate cements nearby the horizontal microfractures, and generated secondary macroporosity. Fluid generation and fluid pressure build up occurred multiple times, and resulted in the swarms of horizontal microfractures observed in middle Bakken core.

\section{Price and Stolper (2000)}

A more convincing argument for in situ propagation of horizontal microfractures was provided by Price and Stolper (2000). By mapping core fractures in slabbed Bakken cores of varying thermal maturities, Price and Stolper (2000) observed:

1) thermal maturity increased open uncemented horizontal microfracture intensity; 


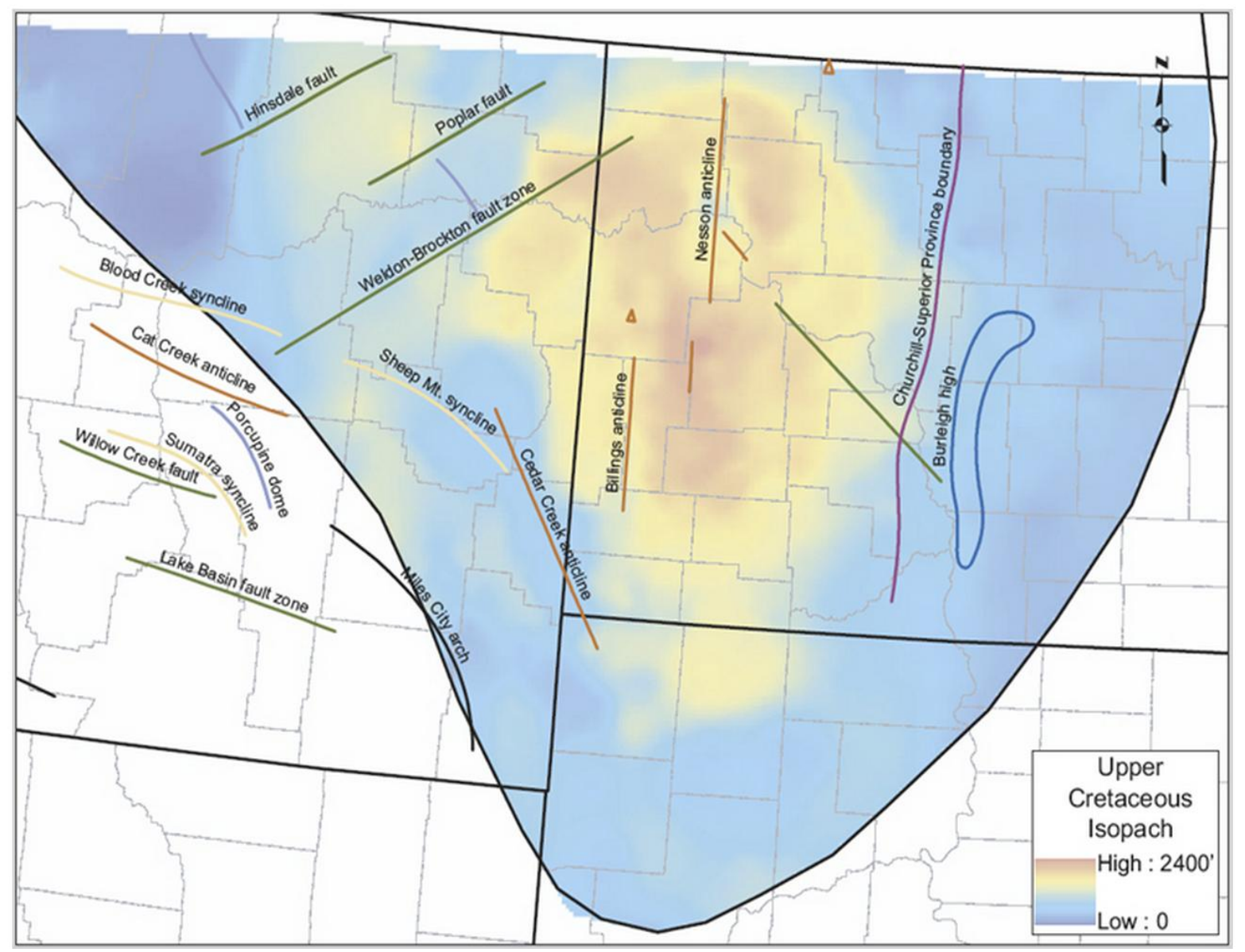

Figure 13: Upper Cretaceous isopach map of US portion of the Williston basin, modified from Flannery and Krauss (2006). Sediment is thinned across the Nesson anticline, which suggests the anticline was active during the late Cretaceous concurrent with Bakken Formation maximum burial depth, burial temperature, and hydrocarbon generation.

2) source-rock proximity increased open uncemented horizontal microfractures intensity;

3) where thermally immature, horizontal microfractures still occurred, but were few and limited to within a few feet of the source-rocks;

4) where thermally mature, horizontal microfractures extended up to 50 feet into the underlying Three Forks and overlying Lodgepole Formations

The Price and Stolper (2000) model provides physical evidence supporting the Pitman et al. (2001) model. Observations 1, 2, and 4 all supports oil generation as the primary 
microfracture propagation driving mechanism. Observation 3 supports pre-thermogenic HDOM reactions (3). Additionally, Price and Stolper (2000) expanded the theoretical framework for superlithostatic fluid pressures by introducing the concept of kerogen compression and decompression.

Price and Stolper (2000) argued that kerogen is highly compressible compared to solid minerals. Immature Bakken shales have $15-25 \%$ TOC by weight, which is equivalent to $30-45 \%$ the shale's volume. According to the Price and Stolper (2000) model, as fluid pressure increases from HDOM and/or thermogenic oil generation, kerogen compresses accordingly. Zeszotarski et al. (2004) demonstrated kerogen from the Woodford shale (type II, marine) behaved in as a viscoelastic material, exhibiting both plasticity and elasticity. Kerogen in the Bakken shales, according the Price and Stolper (2000), slowed the rate of fluid pressure increase by converting fluid pressure to energy in the form of compression. "...when fracturing pressures were finally exceeded and rock failure did occur... this energy of compression would have been instantaneously released, temporarily generating fluid pressures significantly above lithostatic fluid pressures..." (Price and Stolper, 2000). This instantaneous superlithostatic fracturing event is more conceivable than the Pitman et al. (2000) model which does not adequately explain how superlithostatic fluid pressures are maintained up to the point of rock failure.

Both models fail to explain why vertical fractures did initiate as a result of hydrocarbon generation. Stated in another way, the models fail to explain why superlithostatic fluid pressures exclusively generate horizontal microfractures and not vertical microfractures. 


\section{Sea level Curve<smiles>CCCCCCCC</smiles>
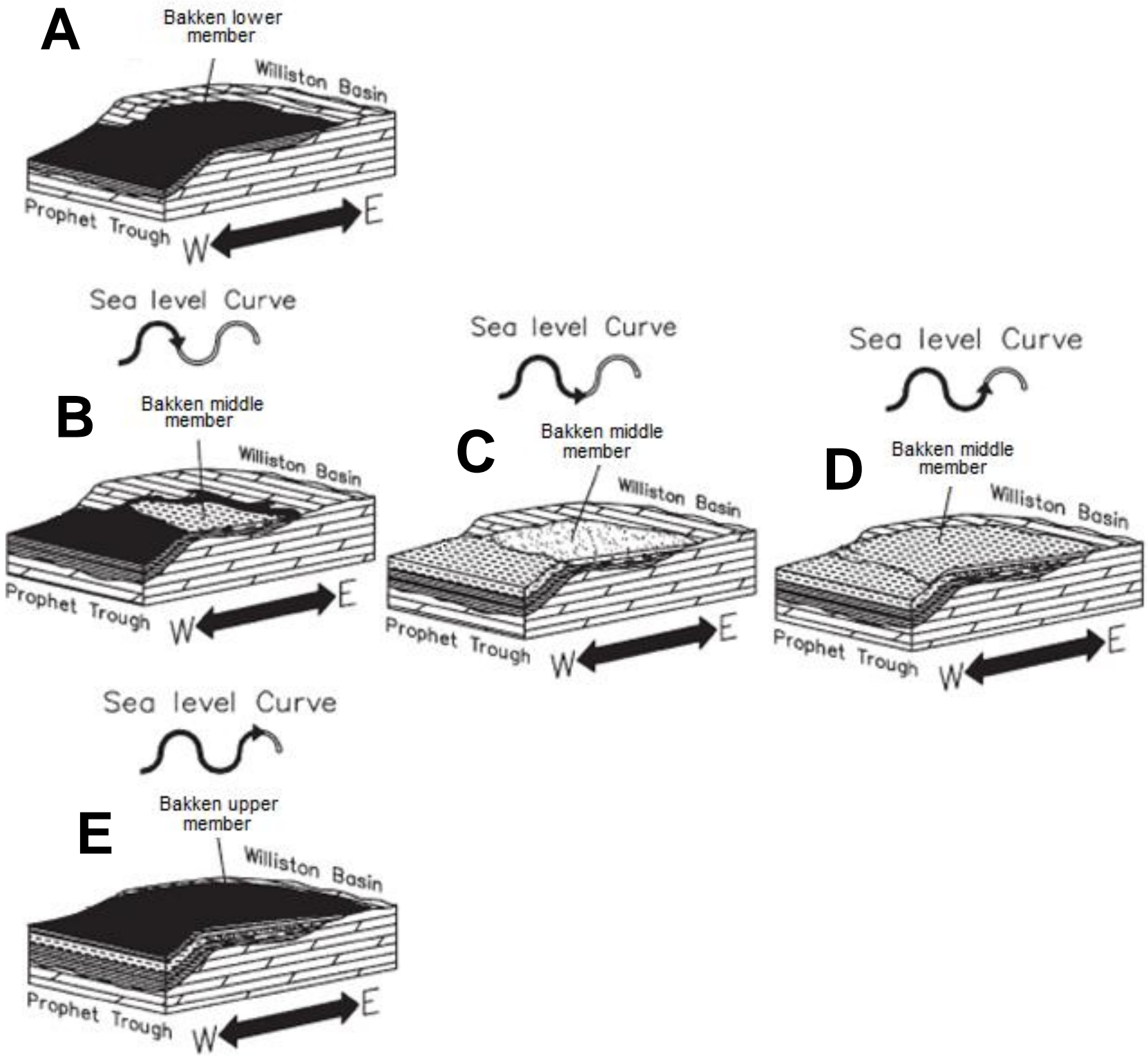

Figure 14: Sequence stratigraphic block models of Bakken Formation deposition on top the Three Forks Formation, modified from Smith and Bustin (2000). Block models are oriented looking northeast across the Williston basin; to the West is Prophet Trough, infilled with Bakken equivalent formations. A) The Bakken lower member was deposited during transgression and highstand. B, C, and D) The Bakken middle member deposition occurred during regression, lowstand, and beginning of a second transgression. E) The Bakken upper member deposition during second transgression and highstand. The Lodgepole Formation limestones (not shown) cap the Bakken Formation during the following regression. 


\section{DISCUSSION}

The common argument against natural (i.e. in situ; at depth; subsurface) horizontal fracture propagation (Hobbs et al., 1976) is the classical mechanics concept that when the maximum stress is oriented vertically due to overburden, fluids cannot exist at superlithostatic fluid pressure. Rock matrix failure would occur as fluid pressures approached lithostatic pressure, resulting in vertical fractures parallel to the maximum pressure, and the process would repeat. The Price and Stolper (2000) kerogen compression model attempted to bypass this impossibility. However, no evidence is supplied to support instantaneous kerogen decompression. It is entirely feasible that, assuming kerogen compression/decompression is a natural phenomenon, the decompression release of energy would never generate superlithostatic fluid pressures because rock failure would occur prior to lithostatic fluid pressures ever being reached.

Opponents of natural horizontal microfractures in the Bakken middle member have cited pressure-release exfoliation jointing as the cause of the fractures (Jump, 2009). As Bakken core is brought to the surface, confining pressure is decreased. The greatest magnitude of pressure decrease is in the vertical direction, as that was the maximum present day stress orientation. The result is mode I jointing perpendicular the vertical axis, resulting in induced horizontal microfractures. Because they are propagated at surface temperatures and pressures, and never subjected to fluid flux, the fractures are open and uncemented.

Neither side of the argument has given proper attention to the tectonic paleostress environment at the time of Bakken oil generation. As noted in the 


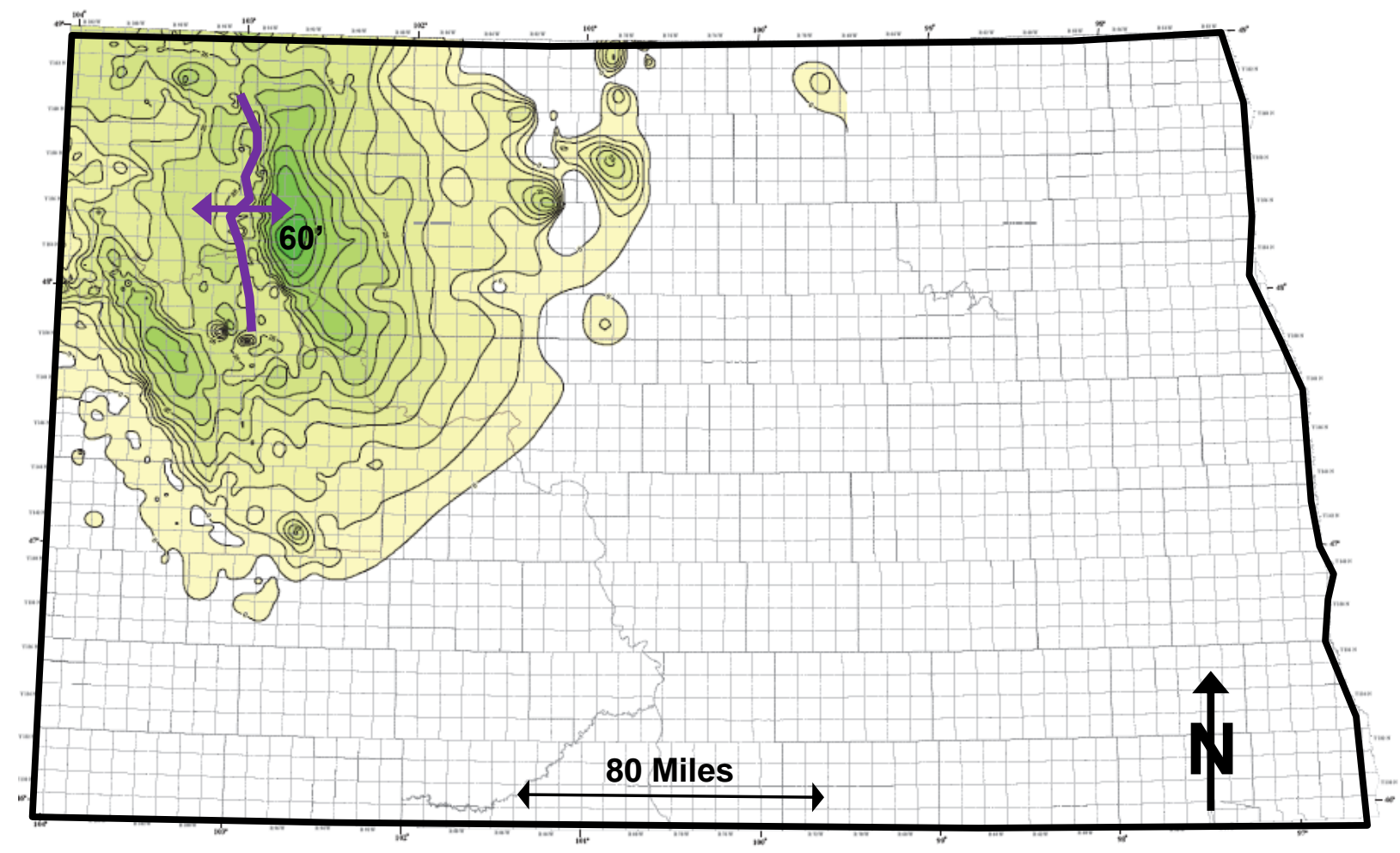

Figure 15: Bakken lower member isopach map in North Dakota, modified from LeFever (2008). Contours range from 0 to 60 feet; the contour interval is 5 feet. The Nesson anticline axis is marked in purple. The lower member reaches its thickest East of the Nesson anticline axis.

Introduction and Geologic Setting, the Nesson anticline was actively uplifted during the late Cretaceous (Flannery and Krauss, 2006; Thomas, 1974) (Figs.). At the same time, the Bakken was buried to its maximum depth within the oil window (Pitman et al., 2001) (Figs.). If the far-field Laramide tectonism responsible for Nesson anticline growth generated a maximum horizontal stress regime, then joint propagation in the Bakken during the late Cretaceous would have likely been horizontal. This is an attractive explanation for horizontal microfracture propagation which is overlooked by proponents of natural horizontal microfractures within the Bakken middle member. Marquez and Mountjoy (1996) attributed horizontal bitumen-filled microfractures in the Devonian Leduc Formation of the Alberta basin to the same process. I argue Laramide far-field tectonism contemporaneous with Bakken oil generation is the best mechanism to 
explain natural horizontal microfractures in the Bakken formation. Furthermore, this mechanism does not require unsupportable superlithostatic fluid pressures. 


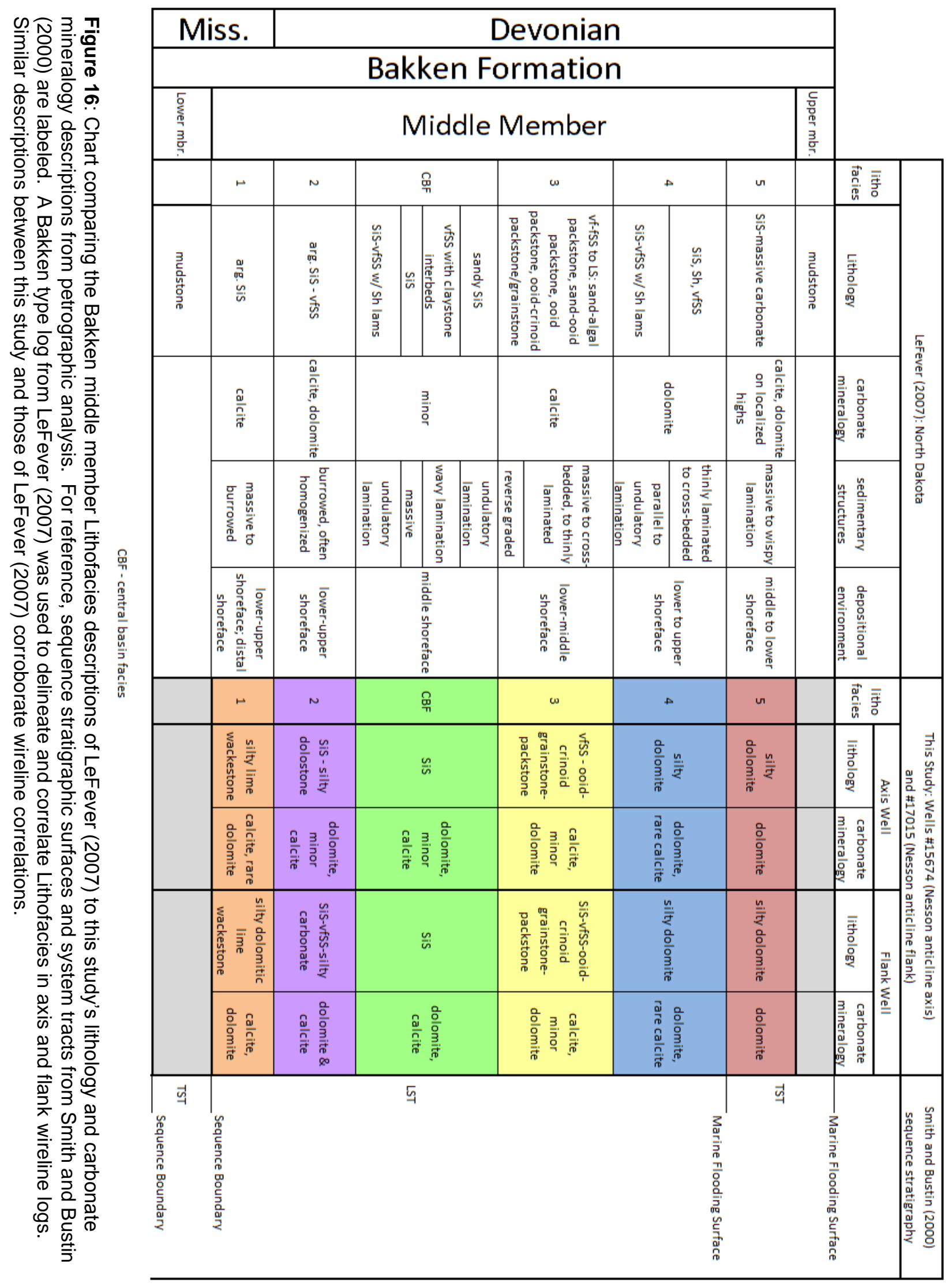




\section{4: METHODS}

Two Bakken Formation cores from wells near the center of the Williston basin were chosen for this study (Fig. 3). The first core is North Dakota Geological Survey Core Library File \#15674. The core is from a well named State 36-31H (API\# 3310501527), originally operated by Amerada Hess Corporation. The well is located in the Beaver Lodge field of the Williston basin, along the Nesson anticline axis (Figs. 3B, 3C). This well will be referred to in this text as the 'axis well'. Its core will be referred to as the 'axis core'.

The second core is North Dakota Geological Survey Core Library File \#17015. The core is from a well named Nesson State 42X-36 (API\# 3110501667), originally operated by Headington Oil Company, LLC. The well is located 6 miles East of the axis well, on the flank of the Nesson anticline (Figs. 3B, 3D). This well will be referred to in this text as the 'flank well'. Its core will be referred to at the 'flank core'.

Wireline logs from both wells (Figs. 21, 22) through the Bakken Formation were correlated to a type log (LeFever, 2007) (Fig. 20), and then correlated to one another.

A total of 50 samples were taken from each of the two cores with care to sample each Bakken member and each lithofacies within the middle member. Thirty samples were taken from the flank well, 20 from the axis well. The disparity in number of samples collected per well is due to the flank well having a thicker Bakken Formation than the axis well. Sampling was restricted to the back side of rocker slabs to preserve the core face. Obtaining billets for thin-section analysis from the highly fissile upper and lower members in the axis core was impossible; instead small shard were collected for potential X-ray diffraction and electron microscope analyses. 


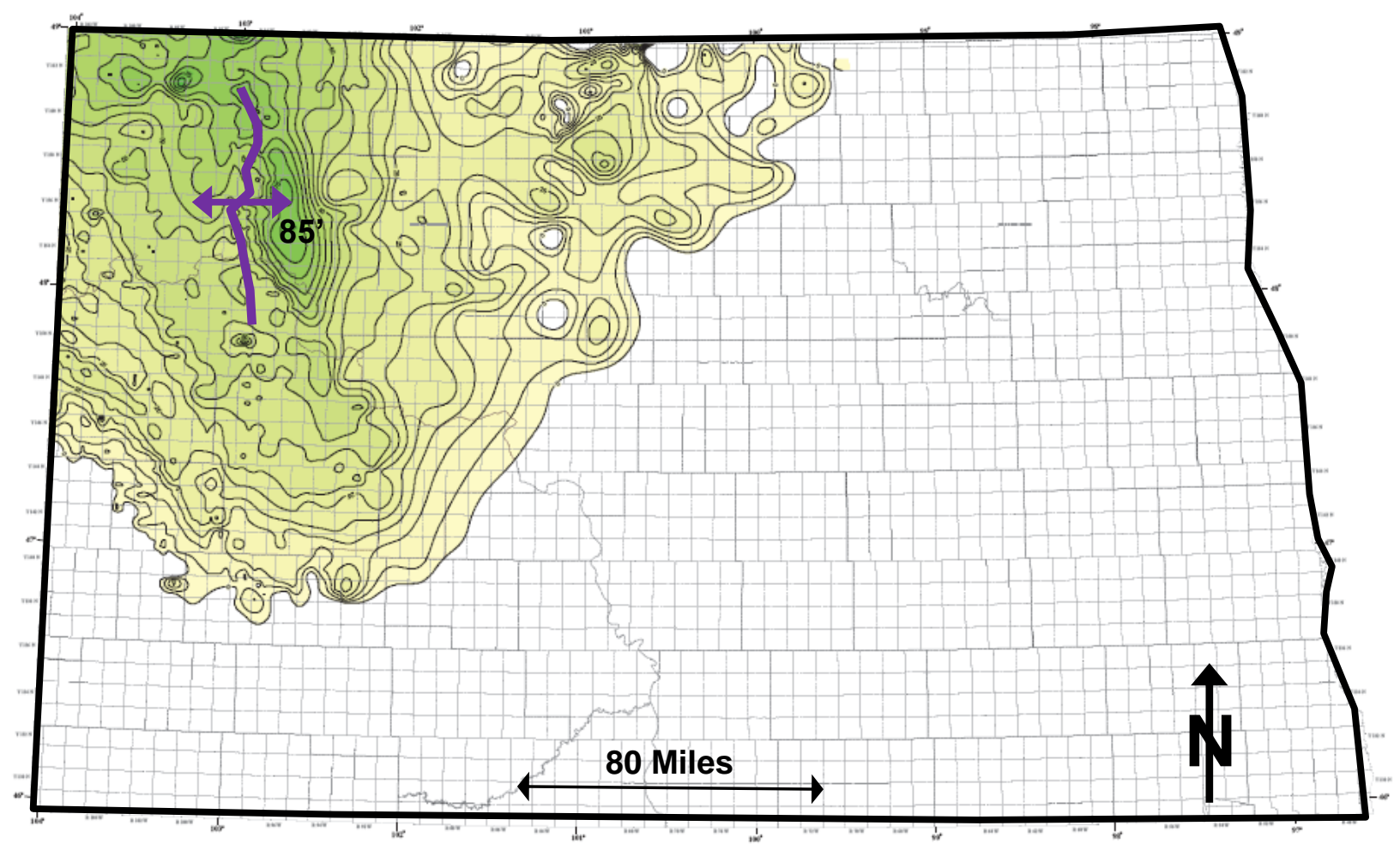

Figure 17: Bakken middle member isopach map in North Dakota, modified from LeFever (2008). Contours range from 0 to 85 feet; the contour interval is 5 feet. The Nesson anticline axis is marked in purple. The middle member reaches its thickest East of the Nesson anticline axis, similar to the lower member.

Thin-sections were prepared by TPS Enterprises. Thirty-one middle member sections were prepared to a standard 30 micron thickness. These samples were stained on one half, perpendicular to bedding direction, with alizarin red-S and potassium ferricyanide for ferroan-calcite and ferroan-dolomite identification. Middle member thinsections were described, photographed, and point-counted for mineral content and macroporosity. Descriptions closely match the Lithofacies descriptions of LeFever (2007), and are summarized in Figure 16. Point-counting involved at least 300 counts with a polarizing light microscope (Table 1). Additionally, horizontal microfractures were characterized, and counted if interpreted as 'natural' horizontal microfractures (HMFs) (Table 1). The length of the thin section rock sample was measured for horizontal 


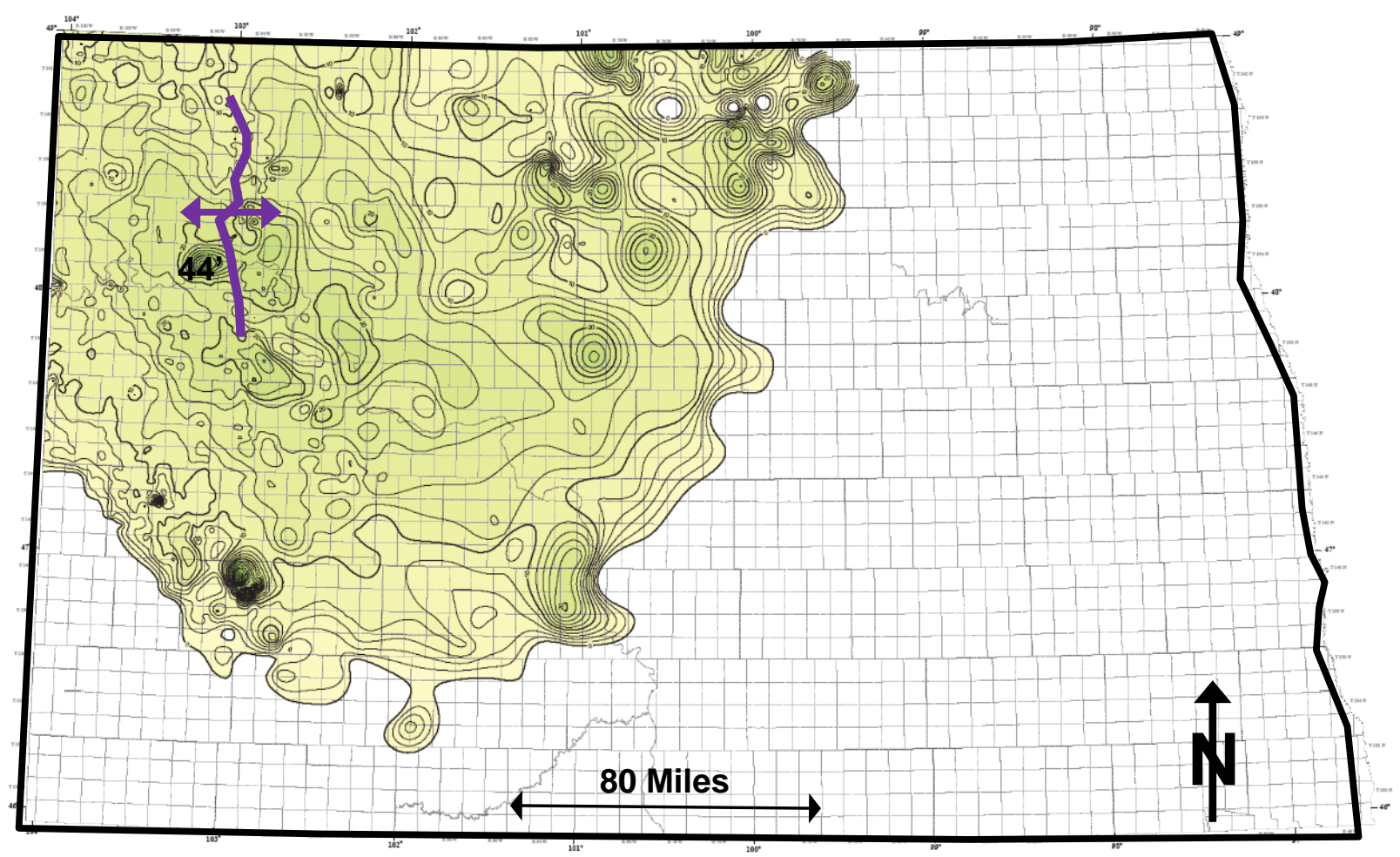

Figure 18: Bakken upper member isopach map in North Dakota, modified from LeFever (2008). Contours range from 0 to 44 feet; the contour interval is 2 feet. The Nesson anticline axis is marked in purple. There is no clearly defined depocenter, and thicks are highly localized relative to the lower and middle member isopachs.

microfracture density calculations (Table 1).

Eighteen upper and lower member sections were wedged, from 30 microns on one side to 0 microns on the other in hopes of viewing the particles smaller than 30 microns as the sample thins to zero. Select upper and lower member sections were made ultra-thin, approximately 20 microns thickness, purely to evaluate the effectiveness of wedged sections. As this study progressed, shale petrography became outside the scope of study. However, it is my opinion that both wedged and ultra-thin thin-sections are useful for the petrographic examination of organic-rich shales. Both were sufficient to reveal clay matrix fabric and expose silt and carbonate grains finer than 30 microns. In standard thin-sections (30 microns thick), these finer grains are 
often completely immersed in dark or opaque clay-sized minerals and rarely transmit light. Eleven upper and lower member shale samples were analyzed by X-ray diffraction (XRD) and thermogravimetry to determine mineralogy and total organic carbon (TOC); TOC results are found in Table 2.

The epoxy used in the thin-section preparation was spiked with a fluorochrome (excitation: $371 \mathrm{~nm}$, emission: $435 \mathrm{~nm}$ ) to aid in porosity observation under epifluorescent UV light (Yangus and Dravis, 1985). Epifluorescence, or reflected light fluorescence, is a technique in which light of a certain wavelength strikes a specimen on a petrographic microscope from above, which absorbs the light and reflects light of a longer wavelength. Porosity, filled with fluorescent dye-spiked epoxy, is revealed in this way (Figs. 8B, 9). 


\begin{tabular}{|c|c|c|c|c|c|c|c|c|c|c|c|c|c|c|c|c|c|c|c|c|c|c|c|c|c|c|c|c|c|c|}
\hline \multicolumn{3}{|c|}{ Samples } & \multicolumn{17}{|c|}{ Raw point count data (counts) } & \multicolumn{5}{|c|}{$\begin{array}{c}\text { Bulk Lithology } \\
\text { Percentages }\end{array}$} & \multirow[b]{2}{*}{ 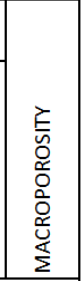 } & \multicolumn{3}{|c|}{ HMF Data } & \multicolumn{2}{|c|}{$\begin{array}{c}\text { Source-rock } \\
\text { Proximity } \\
\end{array}$} \\
\hline$\overline{\overline{0}}$ & $\frac{0}{\frac{0}{0}}$ & 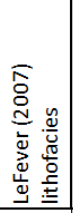 & $\begin{array}{l}\frac{\overline{0}}{0} \\
\overline{0} \\
\text { 응 } \\
\text { 음 }\end{array}$ & 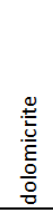 & 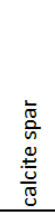 & 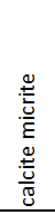 & $\begin{array}{l}\frac{t}{U} \\
\frac{\mathrm{L}}{\mathrm{U}}\end{array}$ & 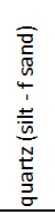 & 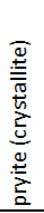 & 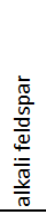 & $\begin{array}{l}\mathscr{U} \\
\frac{\pi}{U} \\
\frac{0}{60} \\
\frac{\pi}{2}\end{array}$ & 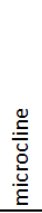 & 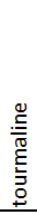 & 은 & 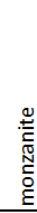 & 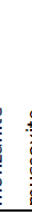 & 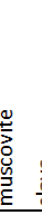 & $\frac{n}{\frac{\pi}{U}}$ & 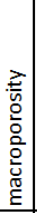 & 岕 & $\begin{array}{l}\stackrel{U}{E} \\
\sum_{0} \\
0 \\
0\end{array}$ & 屶 & 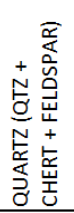 & $\begin{array}{l}\text { 㟶 } \\
\frac{\partial}{2}\end{array}$ & & 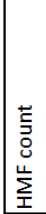 & 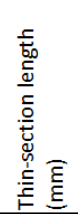 & 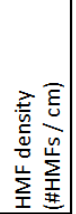 & 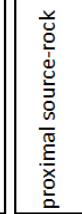 & 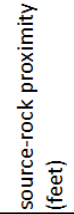 \\
\hline flank & 10314.10 & 5 & 249 & 2 & 0 & 0 & 0 & 30 & 20 & 1 & 0 & 1 & 0 & 0 & c & 0 & 2 & 0 & 0 & 305 & $82 \%$ & $60 \%$ & $10 \%$ & $7 \%$ & $0.0 \%$ & & 19.5 & 0.0 & upper & 0.80 \\
\hline flank & 1 & 5 & 226 & 0 & 1 & 0 & 0 & 57 & 31 & 0 & 0 & 0 & 0 & 0 & & & 2 & 0 & 0 & 317 & $71 \%$ & $0 \%$ & $18 \%$ & $10 \%$ & $0.0 \%$ & & 19.0 & 2.6 & pper & 1.45 \\
\hline flank & 10317.50 & 4 & 241 & 17 & 1 & 4 & 0 & 47 & 21 & 0 & 0 & 0 & 0 & 0 & c & 0 & 1 & 0 & 11 & 343 & $78 \%$ & $2 \%$ & $14 \%$ & $6 \%$ & $3.2 \%$ & 1 & 16.0 & 0.6 & upper & 4.20 \\
\hline flank & 10319.00 & 4 & 220 & 0 & 4 & 3 & 0 & 57 & 28 & 0 & 0 & 0 & 0 & 0 & & 0 & 0 & 1 & 0 & 313 & $70 \%$ & $2 \%$ & $18 \%$ & $9 \%$ & $0.0 \%$ & 14 & & 5.1 & upper & 5.70 \\
\hline flank & 10325.70 & 3 & 7 & 0 & 270 & 0 & 1 & 49 & 0 & 0 & 0 & 0 & 0 & 0 & c & 0 & 0 & 0 & 0 & 327 & $2 \%$ & $683 \%$ & $15 \%$ & $0 \%$ & $0.0 \%$ & 0 & 28.5 & 0.0 & upper & 12.40 \\
\hline flank & 10337.35 & 3 & 75 & 0 & 138 & 2 & 0 & 91 & 14 & 1 & 0 & 1 & 0 & 0 & c & 0 & 0 & 9 & 0 & 331 & $23 \%$ & $642 \%$ & $28 \%$ & $4 \%$ & $0.0 \%$ & 6 & 35 & 1.7 & upper & 24.05 \\
\hline flank & 10340.40 & 3 & 118 & 0 & 30 & 8 & 0 & 121 & 11 & 0 & 0 & 0 & 0 & 0 & & 0 & 1 & 4 & 8 & 301 & $40 \%$ & $13 \%$ & $41 \%$ & $4 \%$ & $2.7 \%$ & 8 & & 2.3 & upper & 27.10 \\
\hline flank & 10348.10 & $\mathrm{CBF}$ & 97 & 14 & 7 & 48 & 0 & 100 & 29 & 6 & 0 & 1 & 1 & 1 & c & 0 & 0 & 5 & 0 & 309 & $36 \%$ & $18 \%$ & $35 \%$ & $9 \%$ & $0.0 \%$ & 0 & 28.5 & 0.0 & upper & 34.80 \\
\hline flank & 10353.10 & $\mathrm{CBF}$ & 102 & 29 & 41 & 0 & 0 & 115 & 16 & 1 & 0 & 0 & 1 & 0 & & 0 & 0 & 8 & 0 & 313 & $42 \%$ & $6 \quad 13 \%$ & $37 \%$ & $5 \%$ & $0.0 \%$ & 4 & & 1.1 & lower & 34.90 \\
\hline flank & & $\mathrm{CBF}$ & 83 & 10 & 132 & 0 & 0 & 78 & 22 & 0 & 0 & 0 & 0 & 0 & & 0 & 0 & 2 & 0 & | 327 | & $28 \%$ & $40 \%$ & $24 \%$ & $7 \%$ & $0.0 \%$ & 1 & & 0.3 & lower & 30.25 \\
\hline flank & 10363.30 & 2 & 10 & 119 & 107 & 2 & 0 & 73 & 23 & 3 & 0 & 0 & 0 & 0 & 0 & & 0 & 3 & 이 & 340 & $38 \%$ & $32 \%$ & $22 \%$ & $7 \%$ & $0.0 \%$ & 5 & 34.0 & 1.5 & lower & 24.70 \\
\hline flank & 36 & 2 & 0 & 185 & 0 & 17 & 0 & 90 & 11 & 7 & 0 & 0 & 0 & 0 & 0 & & 0 & 4 & 0 & 314 & $59 \%$ & $5 \%$ & $31 \%$ & $4 \%$ & $0.0 \%$ & 8 & & 2.1 & lower & 24.60 \\
\hline ank & 00 & 2 & 144 & 0 & 78 & 0 & 0 & 78 & 11 & 2 & 1 & 0 & 0 & 0 & 0 & & 0 & 5 & 0 & 319 & $45 \%$ & $24 \%$ & $25 \%$ & $3 \%$ & $.0 \%$ & 8 & +1 & 1.9 & lower & 14.50 \\
\hline ank & 10376.00 & 2 & 34 & 90 & 13 & 109 & 0 & 56 & 9 & 0 & 0 & 0 & 0 & 0 & 0 & & 0 & 0 & 0 & 311 & $40 \%$ & $39 \%$ & $18 \%$ & $3 \%$ & $0.0 \%$ & 6 & 28.5 & 2.1 & lower & 12.00 \\
\hline flank & 038 & 1 & 4 & & 9 & 106 & 0 & 35 & 32 & 0 & 0 & 0 & 0 & 0 & 0 & & 1 & 2 & 0 & 311 & $41 \%$ & $37 \%$ & $11 \%$ & $10 \%$ & $0.0 \%$ & 6 & & 2.0 & lower & 2.85 \\
\hline axis & & 5 & 0 & 278 & 2 & 0 & 1 & 5 & 24 & 0 & 0 & 0 & 0 & 0 & 0 & & 0 & 0 & 0 & 310 & $0 \%$ & $1 \%$ & $2 \%$ & $8 \%$ & $0.0 \%$ & 8 & & 2.6 & upper & 0.05 \\
\hline axis & 9771.20 & 4 & 168 & 61 & 0 & 0 & 0 & 29 & 27 & 0 & 0 & 0 & 0 & 1 & 0 & & $\begin{array}{ll}0 & 1\end{array}$ & 194 & 48 & 353 & $75 \%$ & $0 \%$ & $10 \%$ & $9 \%$ & $13.6 \%$ & 1 & 34.5 & 0.3 & upper & 4.90 \\
\hline axis & 9774.70 & 4 & 7 & 210 & 0 & 9 & 7 & 49 & 22 & 0 & 1 & 0 & 0 & 2 & 2 & & 1 & 4 & 6 & 320 & $69 \%$ & $3 \%$ & $18 \%$ & $7 \%$ & $1.9 \%$ & 22 & 3 & 7.3 & upper & 8.40 \\
\hline & & 3 & 53 & 17 & & 1 & 2 & 74 & 8 & 1 & 0 & 0 & 0 & 0 & 0 & & 0 & 41 & 17 & 314 & $24 \%$ & $46 \%$ & $26 \%$ & $\%$ & & 0 & & 0.0 & upper & 11.15 \\
\hline is & 9779. & 3 & 16 & 5 & & 0 & 1 & 48 & 4 & 6 & 0 & 0 & 0 & 0 & 0 & & 0 & 0 & 0 & 339 & $6 \%$ & $76 \%$ & $16 \%$ & $1 \%$ & $0.0 \%$ & 0 & 32.0 & 0.0 & upper & 13.60 \\
\hline axis & 9781.35 & 3 & 9 & 5 & & 17 & 3 & 59 & 2 & 7 & 0 & 0 & 0 & 0 & 0 & & 0 & 0 & 3 & 316 & $4 \%$ & $73 \%$ & $22 \%$ & $1 \%$ & $0.9 \%$ & 6 & , & 2.2 & upper & 15.05 \\
\hline & & 3 & 22 & 0 & & 4 & 0 & 79 & 6 & 5 & 1 & 0 & 0 & 0 & 0 & & 0 & 0 & 1 & 318 & $7 \%$ & $64 \%$ & $27 \%$ & $2 \%$ & $0.3 \%$ & 2 & & 1.1 & upper & 16.80 \\
\hline axis & 9784.00 & 3 & 35 & 10 & 116 & 8 & 0 & 109 & 7 & 12 & 1 & 0 & 0 & 1 & 0 & & 0 & 11 & 12 & 312 & $15 \%$ & $41 \%$ & $41 \%$ & $2 \%$ & $3.8 \%$ & 1 & 14.0 & 0.7 & upper & 17.70 \\
\hline & 9786.75 & 3 & 11 & 2 & 173 & & 1 & 77 & 9 & 5 & 0 & 0 & 0 & 0 & 0 & & 0 & 0 & 3 & 327 & $4 \%$ & $68 \%$ & $26 \%$ & $3 \%$ & $0.9 \%$ & 1 & 33 & 0.3 & upper & 20.45 \\
\hline axis & 9793.60 & $\mathrm{CBF}$ & 56 & 51 & 11 & 19 & 5 & 90 & 20 & 27 & 0 & 0 & 0 & 0 & 0 & & $\begin{array}{ll}0 & 1\end{array}$ & 171 & 15 & 311 & $36 \%$ & $10 \%$ & $41 \%$ & $7 \%$ & $4.8 \%$ & 2 & & 0.6 & lower & 21.40 \\
\hline axis & 9799.95 & 2 & 116 & 20 & 23 & 7 & 0 & 94 & 18 & 40 & 0 & 0 & 0 & 0 & 0 & & 1 & 0 & 1 & 320 & $43 \%$ & $9 \%$ & $42 \%$ & $6 \%$ & $0.3 \%$ & 2 & 21.5 & 0.9 & lower & 15.05 \\
\hline & 9801.80 & 2 & 65 & 4 & 26 & 1 & 0 & 63 & 10 & 34 & 0 & 2 & 0 & 0 & 0 & & 0 & 2 & 3 & 310 & $55 \%$ & $9 \%$ & $32 \%$ & $3 \%$ & $1.0 \%$ & 6 & 33.0 & 1.8 & lower & 13.20 \\
\hline axis & 9805.60 & 2 & 120 & 50 & 28 & 1 & 0 & 72 & 13 & 20 & 0 & 2 & 1 & 1 & 0 & & 1 & 5 & 0 & 314 & $54 \%$ & $9 \%$ & $30 \%$ & $4 \%$ & $0.0 \%$ & 4 & 31.0 & 1.3 & lower & 9.40 \\
\hline axis & 9809.60 & 2 & 173 & 0 & 4 & 28 & 0 & 72 & 10 & 12 & 0 & 0 & 0 & 0 & 0 & & 0 & 1 & 0 & 300 & $58 \%$ & $11 \%$ & $28 \%$ & $3 \%$ & $0.0 \%$ & 27 & 25.5 & 10.6 & lower & 5.40 \\
\hline axis & 9811.00 & 2 & 0 & 206 & 3 & 29 & 8 & 66 & 13 & 0 & 2 & 1 & 0 & 2 & 0 & & 1 & 4 & 6 & 341 & $61 \%$ & $10 \%$ & $23 \%$ & $4 \%$ & $1.8 \%$ & 23 & 28.5 & 8.1 & lower & 4.00 \\
\hline axis & 9813.75 & 1 & 0 & 27 & 250 & 0 & 0 & 23 & 9 & 0 & 0 & 1 & 0 & 0 & 0 & & 0 & 0 & 0 & 310 & $9 \%$ & $81 \%$ & $8 \%$ & $3 \%$ & $0.0 \%$ & 1 & 25.5 & 0.4 & lower & 1.25 \\
\hline
\end{tabular}

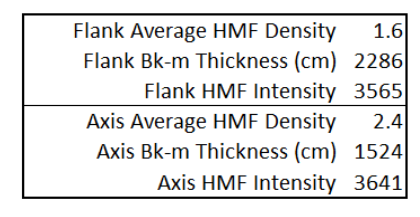

Table 1: Bakken middle member point-count data and calculations from axis and flank well thin section samples. Samples are arranged in descending order by depth. Four species were chosen for bulk mineralogy comparisons: dolomite, calcite, quartz, and pyrite. Bulk mineralogy in this study excluded macroporosity counts. Dolomite is calculated by summing dolospar and dolomicrite counts, and dividing by all mineral counts (excluding macroporosity counts). Similarly, calcite was calculated with calcite spar and calcite micrite counts; quartz was calculated by summing quartz, chert, and feldspars; pyrite used only pyrite counts. Horizontal microfractures with submicroporosity development (HMFs) were counted in each thin section. HMF density was calculated by dividing the HMF count by the vertical thin section length (in $\mathrm{cm}$ ). HMF intensity in each well was calculated by dividing the average HMF density in each core by its middle member thickness. Source-rock proximity is the distance in feet from the sample to the nearest organic-rich shale (either the upper or lower Bakken member contact). 


\begin{tabular}{|c|c|c|c|c|c|}
\hline Analysis & Well & $\begin{array}{c}\text { Sample } \\
\text { depth }\end{array}$ & $\begin{array}{l}\text { Bakken } \\
\text { member }\end{array}$ & $\begin{array}{c}\text { TOC } \\
(w t \%)\end{array}$ & $\begin{array}{c}\text { TOC } \\
(\mathrm{vol} \%)\end{array}$ \\
\hline wvu & flank & 10293.85 & upper & 17 & 28 \\
\hline wvu & flank & 10302.85 & upper & 18 & 30 \\
\hline wvu & flank & 10303.90 & upper & 18 & 30 \\
\hline wvu & flank & 10387.50 & lower & 19 & 31 \\
\hline wvu & flank & 10394.35 & lower & 18 & 30 \\
\hline wvu & flank & 10433.15 & lower* & 6 & 11 \\
\hline wvu & flank & 10434.25 & lower & 15 & 26 \\
\hline wvu & flank & 10436.70 & lower & 18 & 30 \\
\hline $\mathrm{ttk}$ & axis & 9765.40 & upper & 19 & 31 \\
\hline wvu & axis & 9817.90 & lower & 25 & 39 \\
\hline $\mathrm{ttk}$ & axis & 9818.60 & lower & 17 & 28 \\
\hline \multicolumn{6}{|c|}{${ }^{*}$ - metabentonite } \\
\hline \multicolumn{6}{|c|}{ wVu - WVU Physics Dept. thermogravimetry after XRD } \\
\hline
\end{tabular}

Table 2: Total Organic Carbon (TOC) results from the axis and flank wells. Two different methods were used: thermogravimetry performed by the West Virginia University Physics Department, and LECO programmed pyrolysis performed by TerraTek in 2008 (TR08-810439 Petrologic Evaluation of Bakken Shale Core - Nesson 42x-36 Well - Williams County, North Dakota. Prepared for: Headington Oil, LC. Prepared by: TerraTek, A Schlumberger Company); both provided weight percent TOC. Weight percent is converted to volume percent by the following calculation: vol\% $\left.\left(\mathrm{wt} \%_{\mathrm{MIN}} / \rho_{\text {MIN }}\right)\right]$, where $\rho_{\text {TOC }}$ is the average density of kerogen in the Bakken Formation $(1.4 \mathrm{~g} / \mathrm{cc})$ and $\rho_{\text {MIN }}$ is the average density of minerals in the Bakken Formation $(2.72 \mathrm{~g} / \mathrm{cc}$ ) (Price, 2000). The similarity of TOC values between the two members and between the two wells, excluding a metabentonite sample (depth 10433.15'), prevented comparison of HMF density to source-rock organic-richness between the two cores in this study. 


\section{5: RESULTS AND DISCUSSION}

\section{HORIZONTAL MICROFRACTURE CHARACTERIZATION}

\section{Submicroporosity development}

During plane polarized light petrographic examination of the middle member thin sections, some horizontal microfractures were observed to exhibit a blue-green halo above and below the horizontal microfracture aperture (Fig. 8A). The normal background color for the samples was orange-red. Upon examination at higher magnifications, the blue-green color (and the normal orange-red color) appeared associated with grain contacts. Epifluorescence revealed that the blue-green coloration was porosity development above and below the microfracture aperture (Figs. 8B, 9). The inability to resolve this porosity with plane polarized light suggests it is less than one micron wide, and therefore I termed such microfracture related porosity submicroporosity. The association of submicroporosity with only some of the horizontal microfractures suggests this submicroporosity is not a thin-section preparation

phenomenon. Where submicroporosity zones exist, they extend approximately 150 microns above and below horizontal microfracture apertures (Figs. 8B, 9). All horizontal microfractures with submicroporosity zones above and below were open uncemented mode I joints, and are referred through the text as HMFs.

Submicroporosity development suggests a leaching fluid chemistry within the HMF aperture. Such leaching fluid chemistry is most likely to generate secondary porosity if at high temperatures over geologic time, i.e. in situ. It is unlikely that exfoliation fracturing due to coring would generate such secondary submicroporosity. 

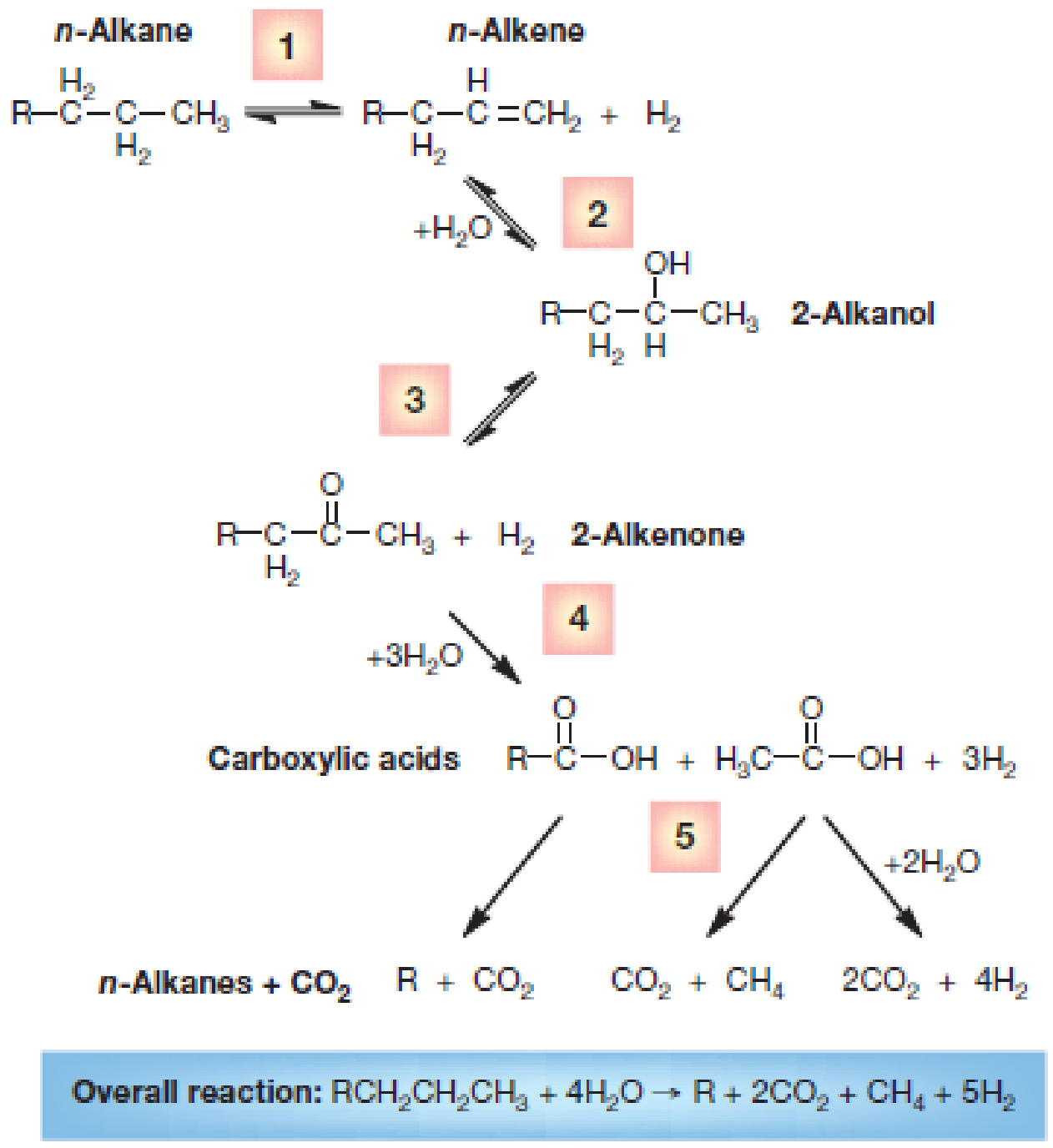

Figure 19: Hydrolytic disproportionation of organic matter (HDOM) idealized chemical reaction pathway (Seewald, 2003). Theoretically this reaction can occur prior to, during, and after thermogenic hydrocarbon generation. Organic matter (in the form of an $n$-alkane) reacts with water to form intermediate carboxylic acids, and ultimately a shorter-chained $n$-alkane, carbon dioxide, methane, and hydrogen. The carboxylic acid intermediates are thought to add to the acidity of any generated fluids; possibly generating secondary porosity during expulsion and migration through carbonate rocks via leaching (Pitman et al., 2001). Carbon dioxide was credited with driving bitumen expulsion from the Bakken source-rocks prior to thermogenic hydrocarbon generation (Pitman et al., 2001). Carbon dioxide and methane are thought to increase fluid pressures. HDOM is posited to be one of the factors leading to superlithostatic fluid pressures thought necessary by Price (2000), Price and Stolper (2000), and Pitman et al. (2001), for natural horizontal microfracture propagation. No conclusive evidence has been found to prove that HDOM occurs in the Bakken Formation. 


\section{Induced fractures}

Other open fractures were noted during petrographic observation, including subvertical open fractures and en echelon-type fractures (Fig. 23). The sense of shear, irregular fracture aperture, and lack of submicroporosity development associated led me to interpret such fractures as induced. I will not refer to induced fractures for the remainder of this text.

\section{HMF density calculation}

Starting at the bottom of each thin section, I counted the number of distinct HMFs in each thin section, and divided this number by the length of rock sampled for each thin section to calculate HMF density for each sample (Table 1):

HMF density $=$ Number of HMFs counted / length (vertical height: $\mathrm{cm}$ ) of thin section

Since HMFs often bifurcate, anastomise, or are discontinuous across the sample (Fig.

9), I counted each discrete horizontal layer dominated by an HMF as $1 \mathrm{HMF}$. For

example, in the view of Figure 9, I counted three discrete, evenly spaced, horizontal layers.

\section{HMF DENSITY COMPARISONS}

Based on the hypothesis that HMFs represent in situ propagation, I compared HMF density to a number of geologic variable in hopes of recognizing trends that would reveal more about the controls on HMF density and location. Variables were:

1) bulk mineralogy percentages (dolomite, calcite, quartz, and pyrite) calculated from point-count data,

2) macroporosity percentages calculated from point-count data,

3) LeFever (2007) Lithofacies, 


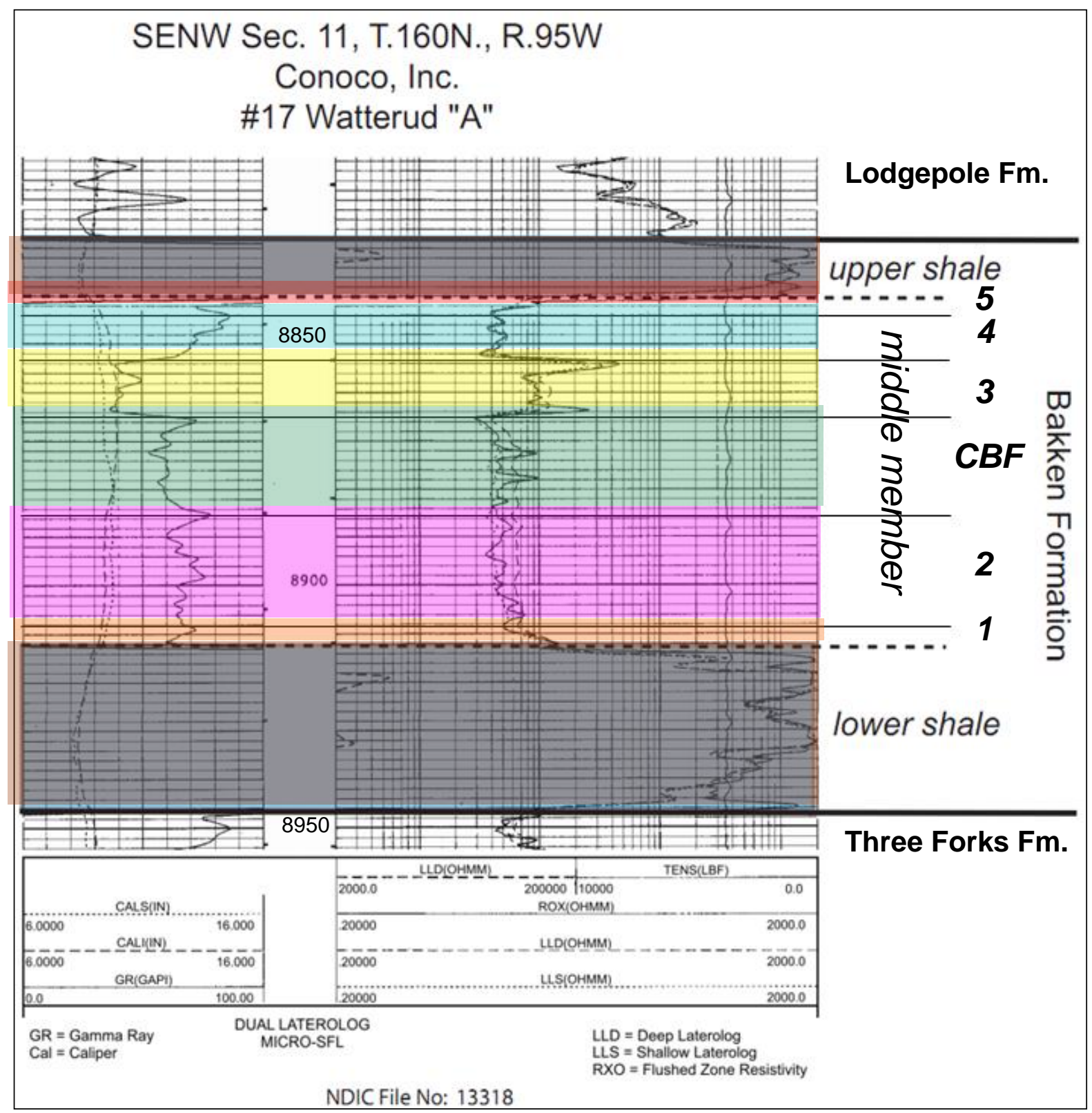

Figure 20: Bakken Formation type log (API\#3302300412, NDGS Library File No. 13318) in North Dakota used by LeFever (2007) to illustrate the 6 middle member lithofacies. CBF is the central basin facies. The well location of this type log is located on the northern tip of the productive Nesson anticline axis, north of the study wells. The Gamma ray response in Track 1 and the lithofacies descriptions of LeFever (2007) were used to correlate this type log to the axis and flank logs from this study. The axis and flank logs were correlated with one another with the aid of additional wireline curves. 
4) middle member thickness (the thickness of the middle member from the core the sample was taken from,

5) source-rock proximity (the distance from the middle member sample to the closest shale member),

6) and source-rock thickness

Thermal maturity and organic richness of the upper and lower members in both cores were similar (Table 2; Fig. 24) and therefore not compared to HMF density.

\section{Bulk mineralogy}

The primary mineral species I point-counted were dolomite (spar and micrite), calcite (spar and micrite), chert, detrital quartz (silt to fine sand), and pyrite (Table 1). Minor minerals point-counted included alkali feldspar, plagioclase, microcline, tourmaline, zircon, monazite, muscovite, and clays. I also point-counted macroporosity.

I determined bulk mineralogy for the four most dominant mineral species I observed in the middle member. For bulk dolomite, I combined all the dolomite counts for a given sample, and divided by the total number of mineral counts for that sample. Similarly, I combined all the calcite counts for bulk calcite. For bulk quartz, I combined the quartz, chert, and feldspar counts. For bulk pyrite, I combined all the pyrite counts. I recorded a percentage for each 'bulk mineralogy': \% dolomite (ranging from 0-85\%), \% calcite (ranging from 0-85\%), \% quartz (ranging from 0-45\%), and \% pyrite (ranging from 0-11\%) (Table 1).

I plotted each sample's four bulk mineral species percentages versus HMF density (Fig. 25). The samples with highest HMF density measurements (greater than 2.6 $\mathrm{HMF} / \mathrm{cm})$ had relatively low bulk calcite $(0-15 \%$, range $0-85 \%)$, relatively high bulk 


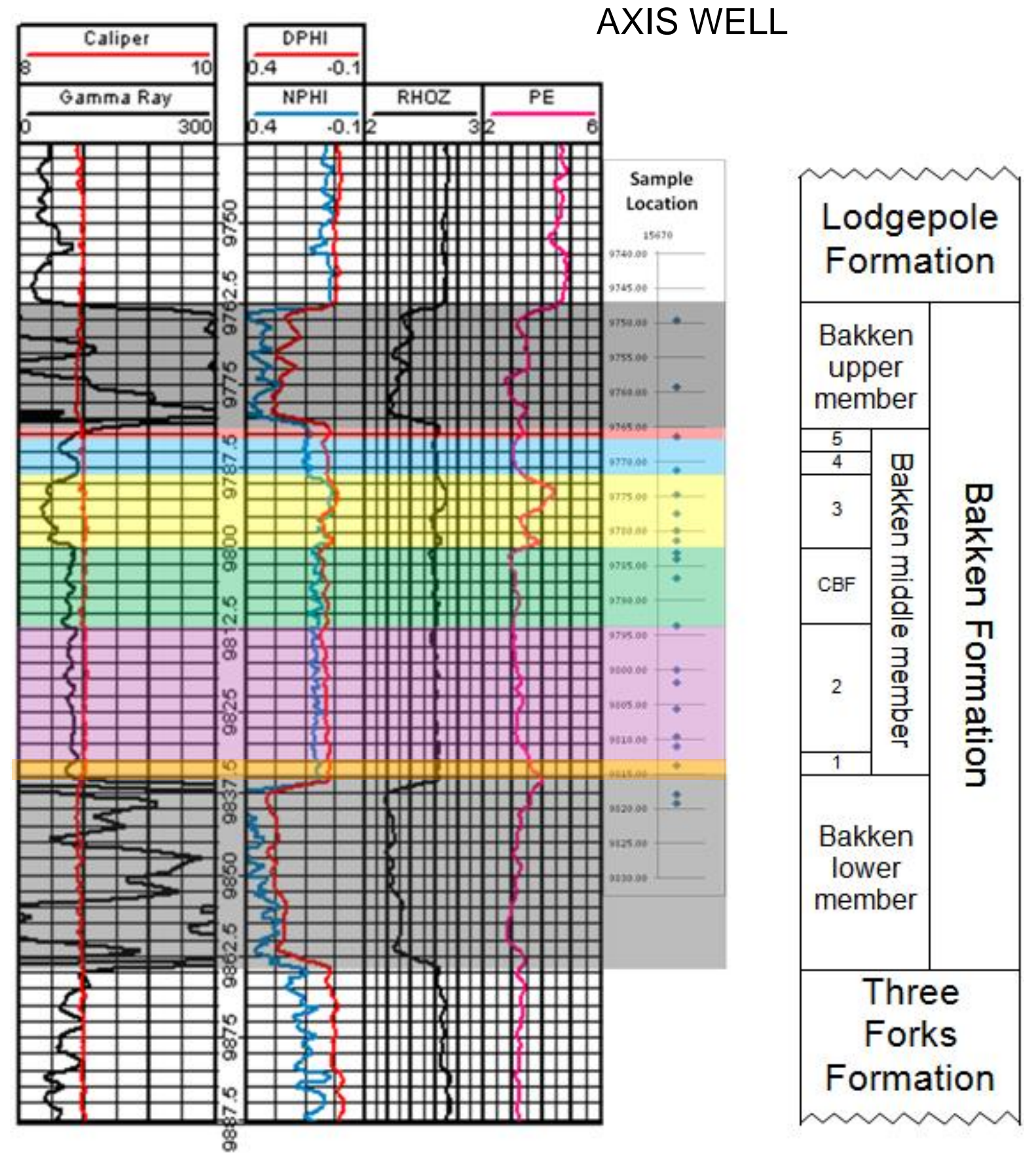

Figure 21: The axis well wireline log with correlated LeFever (2007) lithofacies. Caliper and gamma ray are shown in track 1. Density porosity (DPHI) and neutron porosity (NPHI) are in track 2. Bulk density $(\mathrm{DHOZ})$ is in track 3. Photoelecttric effect (PE) is in track 4. Thin-section sample locations are in the track 5 position. On the right is the interpreted stratigraphic column. Core (and sample) depths are shifted 17.5 feet up from the logged depth. The lower, middle, and upper Bakken members are 30, 50, and 18 feet thick, respectively. 
dolomite (55-90\%, range $0-90 \%)$, and moderate bulk quartz (15-30\%, range of $0-45 \%)$. Bulk pyrite showed no relationship to high HMF density.

The relationship between HMF density, high amounts of dolomite, and low amounts of calcite suggests subsurface in situ HMF propagation. The brittleness of dolomite only exceeds that of calcite at subsurface temperatures and pressures (Handin et al., 1963) (Fig. 26). For example, at the temperature and pressure expected at 10000 feet depth (similar to the axis and flank wells), calcite is $2-4 \%$ ductile, whereas dolomite is $1 \%$ ductile. At surface conditions, both calcite and dolomite have similar $1 \%$ ductility. If the HMFs propagated in the subsurface, dolomitic lithology would be expected to host more HMFs than calcite-rich rocks. If the HMFs propagated at surface conditions via pressure release exfoliation, no disparity between dolomite and calcite would be expected.

\section{Macroporosity}

I calculated percent macroporosity as number of macroporosity counts divided by the total number of counts per sample (Table 1). I define macroporosity in this study as porosity which can be resolved with standard transmitted light optics (greater than 1 micron); excluding fracture aperture-porosity. Submicroporosity, as described associated with HMFs, is also not included in macroporosity measurement.

I plotted each sample's macroporosity against HMF density (Fig. 11). Samples with high HMF density (greater than $4.0 \mathrm{HMF} / \mathrm{cm}$ ) all had less than $2 \%$ macroporosity. All samples with high macroporosity (greater than 3.0\%) have HMF densities less than 1.0 HMF/cm. I interpret this negative relationship as either: 


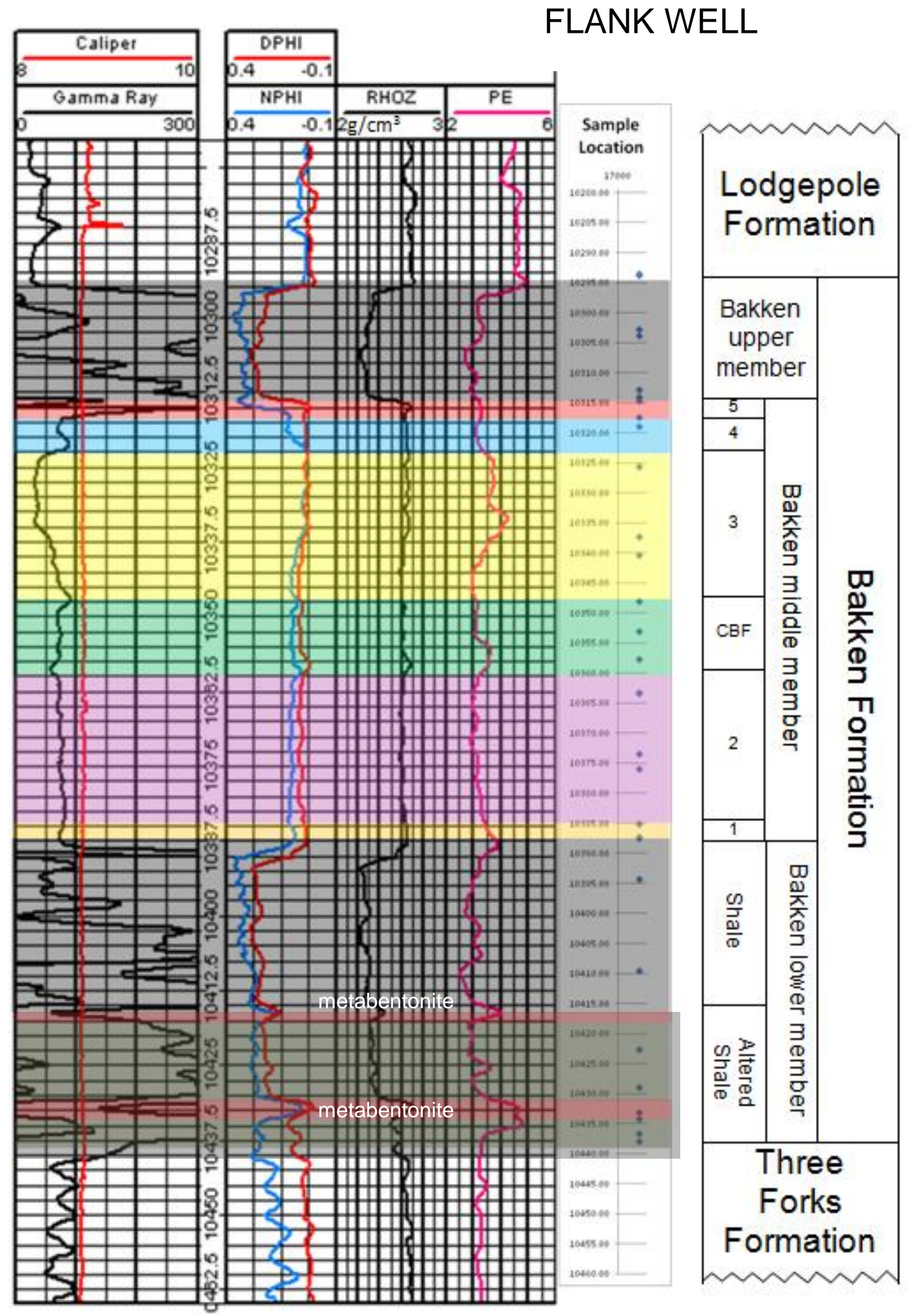

Figure 22: The flank well wireline log with correlated LeFever (2007) lithofacies. Log tracks are the same as the axis well wireline log. The lower, middle, and upper Bakken members are 50, 75, and 20 feet thick, respectively. The lower member has two metabentonites not present in the axis well. 
1) macroporosity has a negative effect on HMF development by preventing fluid pressures from building at the leading edge of fracture propagation.

2) HMF development cements any previous macroporosity by precipitating the minerals leached during submicroporosity development into nearby macropores.

I found no petrographic evidence proving either hypothesis. However, if direct evidence were to be found of macropores being cemented nearby HMFs, it would provide additional support that HMFs propagated in the subsurface. Furthermore, the mineralogy and potential fluid inclusions would be significant in corroborating the proposed natural HMF mechanisms of Pitman et al. (2001), Price and Stolper (2000), and this study. I modified the paragenesis chart from Pitman et al. (2001) to reflect this hypothesis (dashed lines in Figure 7).

\section{LeFever (2007) Lithofacies}

I correlated the type log of LeFever (2007) and its interpreted lithofacies (Fig. 20) to the axis and flank wells' wireline logs (Figs. 21,22). Six lithofacies were correlated in this way. The highest HMF densities are found in lithofacies 2, 4 and 5 (Table 1). These lithofacies are generally within 10 feet of proximity of the source-rock - middle member contacts, and are characterized by their silty dolomitic lithology (Fig. 16). Since both source-rock proximity and dolomite mineralogy have positive relationships with increased HMF density, the affect of the lithofacies by themselves on HMF density is obscured.

Canter et al., (2009) reported preliminary results of an investigation of Bakken microfracture development, and suggested mechanical stratigraphy on the lithofacies- 


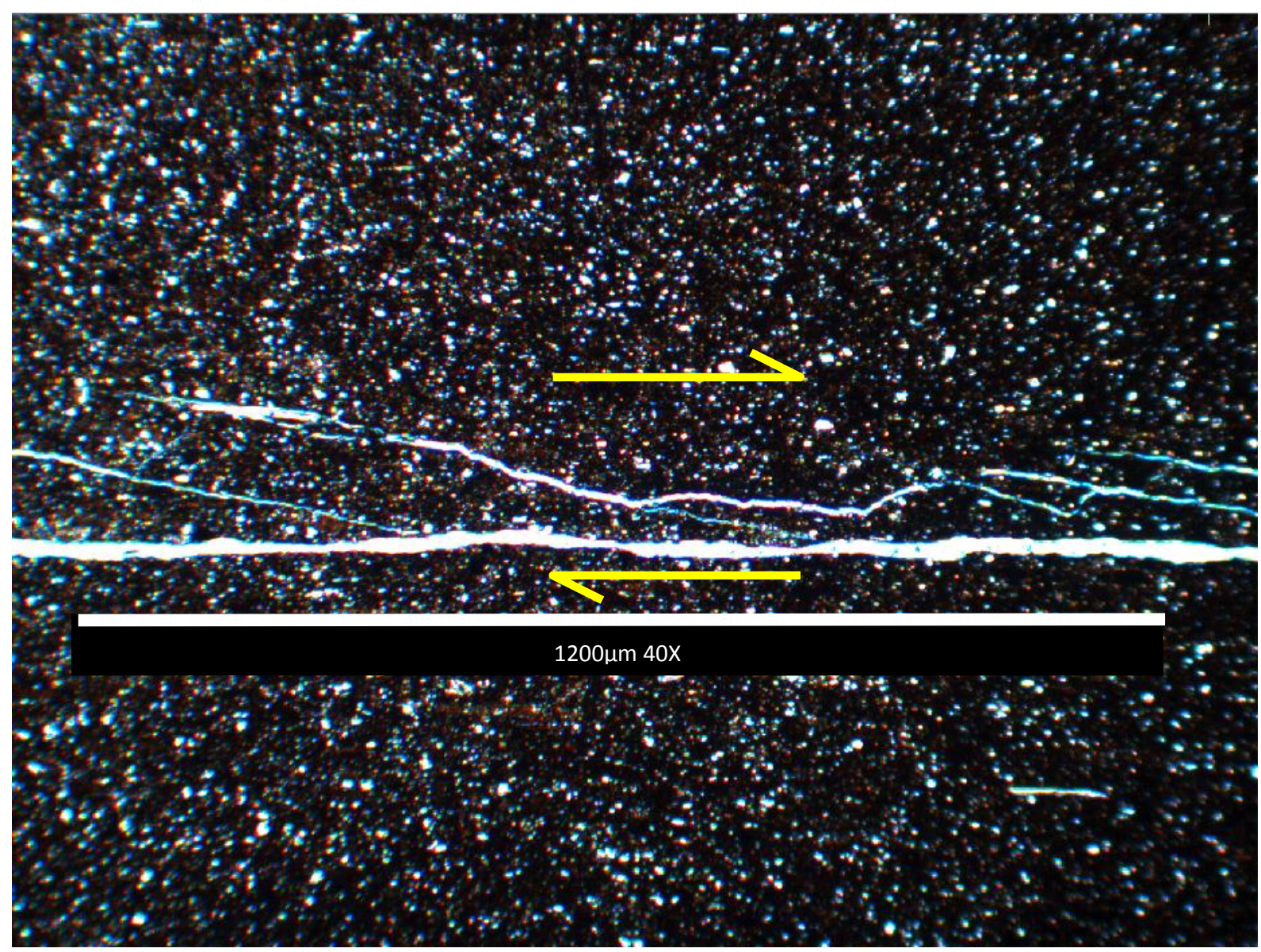

Figure 23: Photomicrograph of typical induced microfractures in an upper Bakken member shale sample at 10302.85' depth from the flank core. En echelon morphology and an irregular horizontal microfracture aperture suggest shear (indicated by yellow arrows). Horizontal microfractures with these characteristics were not counted as HMFs.

scale played a role in middle member microfracture development. I did not attempt to test lithofacies thicknesses against HMF density because I felt that the Lithofacies were chosen based on mineralogy and depofacies changes, not by discrete mechanical boundaries.

\section{Middle member thickness}

The axis well's middle Bakken member is 50 feet thick, one-third thinner than the flank well's 75 foot thick middle Bakken member. Lithofacies 2 and 3 are significantly thicker in the flank well relative the axis well. I averaged HMF density measurements 
for each core, recording the average as 'HMF intensity' (Table 1). HMF intensity in the flank well is $1.6 \mathrm{HMF} / \mathrm{cm}$. HFM intensity in the axis well is $2.4 \mathrm{HMF} / \mathrm{cm}$. For each well, I multiplied HMF intensity by the well's Bakken middle member thickness to estimate the total number of HMFs expected, recorded as 'ideal HMF count'. The flank well has an ideal HMF count of 3566 HMFs. The axis well has an ideal HMF count of 3642 HMFs. Even though the calculation is crude, the fact the ideal HMF counts are quite similar (within $2 \%$ of each other), suggests a potential mechanical stratigraphic control: HMF intensity has a negative correlation with middle member thickness. I suspect ideal HMF count is representative of how much fracture energy was available. Therefore, I would suspect variation of ideal HMF counts with upper and lower Bakken member thermal maturation and organic-richness variations, as increases of these would increase hydrocarbon generation and consequence fluid pressure increases. In this study, the two wells have similar thermal maturity and organic-richness, and thus similar ideal HMF counts are not surprising.

\section{Source-rock proximity}

I calculated source-rock proximity for each sample by taking the difference between the sample depth and the depth of the nearest middle member contact with either the upper or lower Bakken member shale (Table 1). I plotted this distance in feet versus HMF density (Fig. 10). Samples with high HMF density (greater than 4.0 $\mathrm{HMF} / \mathrm{cm}$ ) were all within 10 feet of the nearest source rock. This positive relationship between HMF density and source-rock proximity agrees with the models proposed by Pitman et al. (2001) and Price and Stolper (2000) that oil generation and migration from 


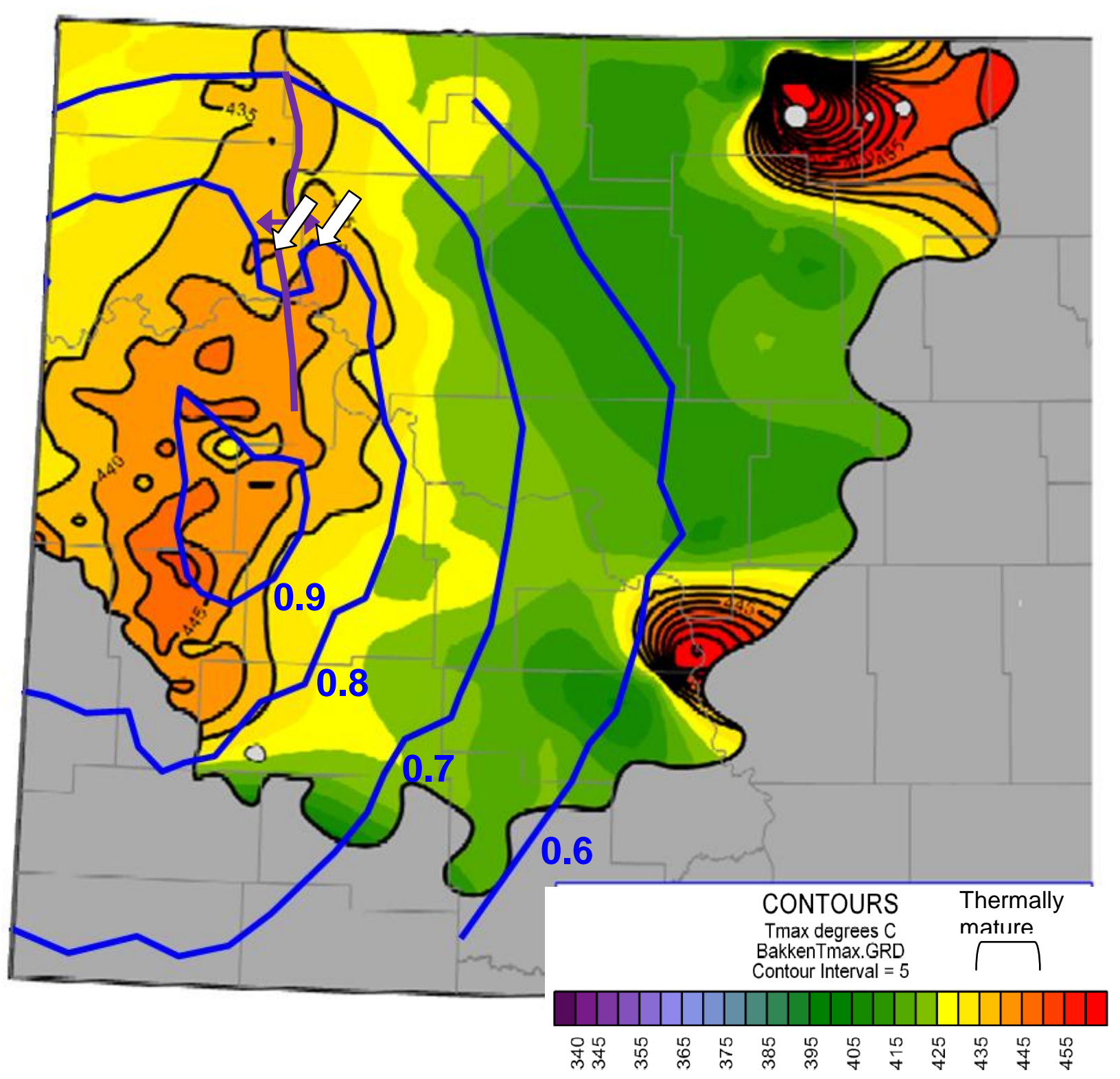

Figure 24: Map of Bakken Formation shale thermal maturity in northwest North Dakota, modified from Nordeng and LeFever (2009) and Flannery and Krauss (2006). The color-filled contours represent RockEval $\mathrm{T}_{\operatorname{MAX}}\left({ }^{\circ} \mathrm{C}\right)$ values ranging from 335 to $465^{\circ} \mathrm{C}$, at a contour interval of $5^{\circ} \mathrm{C}$ (Nordeng and LeFever, 2009). $\mathrm{T}_{\text {MAX }}$ values from 435 to $450^{\circ} \mathrm{C}$ are interpreted as thermally mature, i.e. in the oil window. Heavy blue contours are modeled vitrinite reflectance (\%Ro) ranging from $0.6-0.9 \%$ Ro (Flannery and Krauss, 2006). Vitrinite reflectance values of $0.6-1.35 \%$ Ro are considered thermally mature. The axis and flank study wells both lie near the $440^{\circ} \mathrm{C} \mathrm{T}_{\operatorname{MAX}}$ contour and the $0.8 \%$ Ro contour, suggesting both have similar thermal maturity in the oil window, and preventing comparisons between HMF density and thermal maturity between the two cores. 


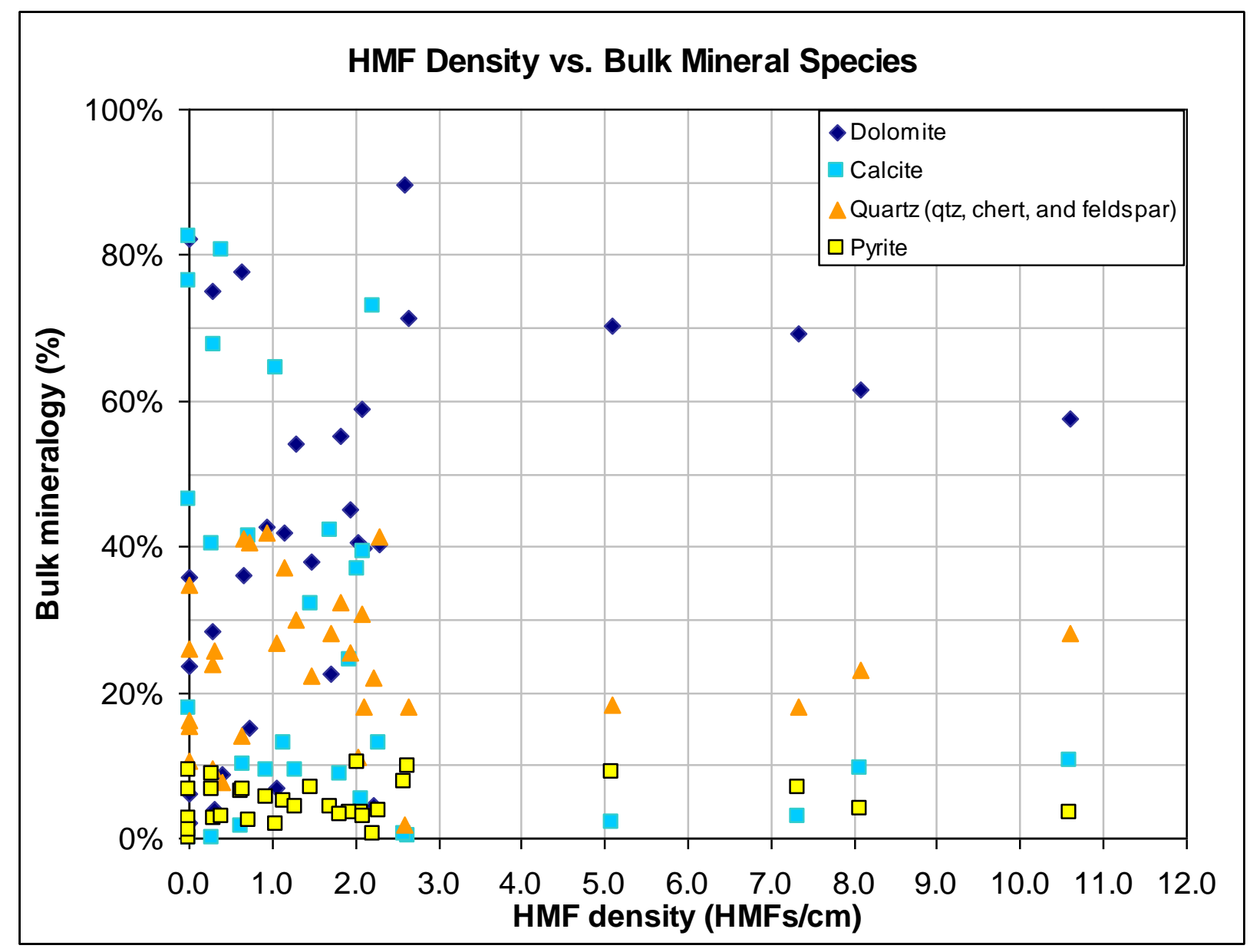

Figure 25: Plot of Bakken middle member HFM density versus the four dominant mineral species. Each point represents one sample. The axis and flank wells are each represented. Bulk mineral species percentages were calculated from point-count data, excluding macroporosity. Bulk quartz combines quartz, chert, and feldspar. HMF density is the vertical density of submicroporosity-zoned horizontal microfractures for each sample. Dolomite ranges from $0-95 \%$, calcite ranges from $0-85 \%$, quartz ranges from $0-45 \%$, and pyrite from $0-10 \%$. Samples with HMF density greater than $2.6 \mathrm{HMF} / \mathrm{cm}$ have relatively high percentages of dolomite ( $55-90 \%)$, relatively moderate quartz $(\sim 15-30 \%)$, and relatively low calcite (less than 15\%). Pyrite does not seem to vary from its normal range in high HMF density samples. 
the hydrocarbon source-rocks are a primary driving force which propagated horizontal microfractures.

\section{Source-rock thickness}

Price (2000), Price and Stolper (2000), and Pitman et al., (2001) all concluded that factors which increased hydrocarbon generation likely controlled the intensity of natural horizontal microfracturing. Increases in source-rock thickness, organic-richness, and thermal maturity would all increase the amount of hydrocarbons produced, and therefore increase the fluid pressures thought to drive horizontal microfracture propagation.

As previously discussed, the thermal maturity and organic-richness of the Bakken upper and lower member shales in both the axis and flank well are relatively similar (Fig. 24, Table 2). The upper member in both axis and flank wells is similar in thickness (18 and 20 feet, respectively). The lower member, on the other hand, is significantly thicker in the flank well (50 feet) than in the axis well (30 feet) (Figs. 21, 22). The flank well should therefore exhibit roughly 1.7 times more middle member horizontal microfractures than the axis well, given similar organic-richness and thermal maturity. However, similar HMF intensity measurements between the two cores (Table 1) suggests the energy for microfracturing was similar between the two wells. Thus it appears source-rock thickness alone does not control HMF intensity.

\section{SUMMARY}

Submicroporosity development suggests HMFs are naturally-occurring, that is to say in situ. HMF relationships with source-rock proximity and mineralogy also support natural-propagation. The thickness of the middle member appears to play an inverse 
role in HMF propagation intensity. To my knowledge, these four observations are currently unrecognized in the literature. Macroporosity also appears to have a negative correlation to HMF density.

The study was not well designed for comparison of Bakken upper and lower member source-rock variations because thermal maturity and organic-richness were similar between the axis and flank wells. With that in mind, overall source-rock thickness does not seem to affect HMF intensity, and thus unlikely affects HMF density. However, proximity to the source-rock, within ten feet in this study, appears to heavily control the location of HMF-dense zones. I agree, therefore, with Price (2000), Price and Stolper (2000), and Pitman et al. (2001) that 1) some HMFs are naturally-occurring, and 2) hydrocarbon generation was a driving force for HMF propagation. If hydrocarbon generation was a driving force, and the Bakken is typically organic-rich throughout the basin, then thermal maturity is likely the only major upper and lower-member lithologic control on HMF generation. 


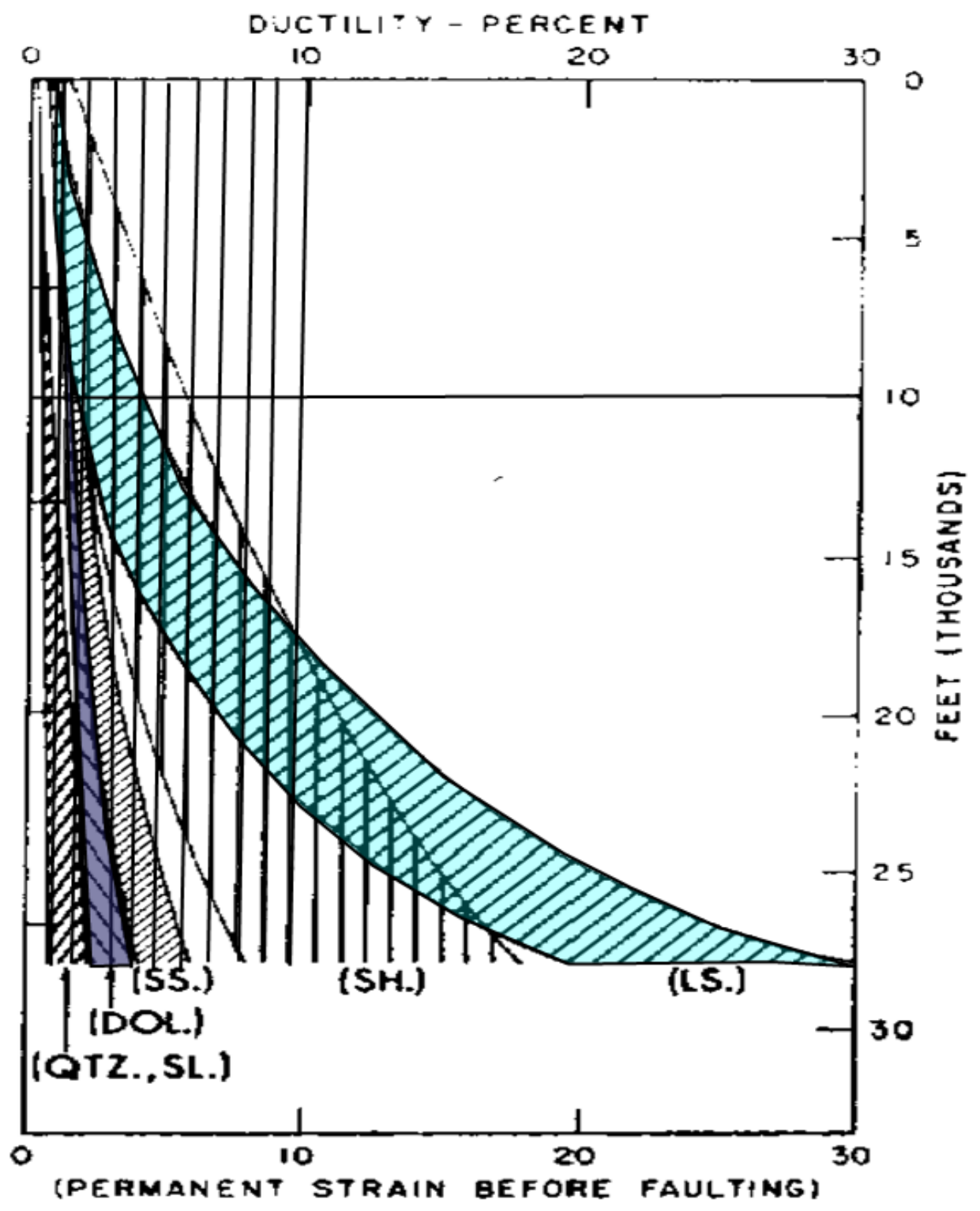

Figure 26: Plot of ductility vs. depth of water saturated rocks for varying lithologies (modified from Handin et al., 1963). Standard geothermal and lithostatic gradients were used to estimate the y-axis depth. Limestone (shaded blue) is 2 to $4 \%$ ductile at depths similar to the axis and flank well Bakken Formation (10000 feet), while dolomite (shaded purple) is 1.5\% ductile at the same depth. At surface conditions, ductility measurements of the two lithologies are similar (less than 1\%). The association between increased HMF density, increased dolomite (greater than 50\%), and decreased calcite (less than 10\%), can be explained if HMFs propagated at depths where dolomite was significantly more brittle than calcite. The axis and flank wells are at such depths. 


\section{6: CONCLUSIONS}

Submicroporosity, source-rock proximity, increased dolomite, decreased calcite, and decreased macroporosity relationships together all point to natural in situ propagation of Bakken middle member HMFs. The Marquez and Mountjoy (1996) model of Laramide Orogeny far-field tectonism contemporaneous with maximum hydrocarbon generation is supported by the Bakken Formation burial history curve (Pitman et al., 2001), Nesson anticline truncation by basement lineaments (Thomas, 1974), and late Cretaceous sediment thinning over the anticline axis (Flannery and Krauss, 2006). The Marquez and Mountjoy model (1996) adequately explains the natural, in situ, propagation of oil-wet, mode I, horizontal microfractures. Therefore, the superlithostatic fluid pressure HMF propagation mechanism as explained in previous studies (Price, 2000; Price and Stolper, 2000; and Pitman et al., 2001) is not necessary in my opinion. Similarly, the specific theories inherent to generating superlithostatic fluid pressures like carbon dioxide production from hydrolytic disproportionation of organic matter (Pitman et al., 2001; Price 2000), and instantaneous kerogen decompression (Price and Stolper, 2000) are not necessary.

Further research is recommended to better understand the generation of the submicroporosity observed associated with some Bakken middle member horizontal microfractures. I assume organic acids in oil are responsible for submicroporosity development.

The aperture of HMFs in the subsurface present day is likely zero, as far-field Laramide orogeny horizontal stresses ceased long ago and the maximum stress is now oriented vertically. Pressure release exfoliation likely reopens apertures, explaining the 
conclusions that Bakken middle member horizontal microfractures are induced.

Submicroporosity suggests the zones around HMF apertures are porous and to some extent permeable. Therefore, horizontally-oriented submicroporosity zones, evident as horizontal microfractures in core, and HMFs in thin-section, may be a new reservoir concept in the Bakken. It is unclear if this type of fractured-reservoir is as important to Bakken production as previous studies have suggested. 


\section{7: REFERENCES CITED}

Bachu and Hitchon, 1996. Regional-scale flow of formation waters in the Williston basin. AAPG Bulletin, Vol. 80 , No. 2. p. 248-264.

Beaumont et al., 1987. The Alleghenian orogeny and its relationship to the evolution of the eastern interior, North America, in Beaumont \& Tankard, eds., Sedimentary basins and basinforming mechanisms. Canadian Society of Petroleum Geologists Memoir 12, p. 425-445.

Canter et al., 2009. Facies and Mechanical Stratigraphy of the Middle Bakken, Mountrail County, North Dakota. AAPG Search and Discovery Article \#90092.

Chen et al., 2009. Spatial variation of Bakken or Lodgepole oils in the Canadian Williston Basin. AAPG Bulletin, Vol. 93, No. 6. pp. 829-851.

Dow, 1974. Application of oil-correlation and source rock data to exploration in Williston Basin: AAPG Bulletin Vol. 58, pp. 1253-1262

Dumonceaux, 1984. Stratigraphy and depositional environments of the Three Forks Formation (Upper Devonian), Williston Basin, North Dakota: University of North Dakota Unpublished M.S. Thesis, $189 \mathrm{p}$.

Ferdous, 2001. Regional sedimentology and diagenesis of the Middle Bakken Member: implications for reservoir rock distribution in southern Saskatchewan. PhD thesis, Department of Geological Sciences, University of Saskatchewan.

Flannery and Kraus, 2006. Integrated analysis of the Bakken petroleum system, U.S. Williston basin: AAPG Search and Discovery Article \#1010

Gerhard et al., 1990. Petroleum geology of the Williston Basin, in Leighton et al. Interior cratonic basins, AAPG Memoir 51, pp. 507-559

Gerhard and Anderson, 1988. Geology of the Williston Basin (United States portion), in Sloss, ed., Sedimentary cover - North American craton. Geological Society of America, The Geology of North America, v. D-2, p. 221-241.

Green et al., 1985. Evolution of Proterozoic terrains beneath the Williston Basin. Geology, Vol. 13, p. 624-628.

Handin et al., 1963. Experimental deformation of sedimentary rocks under confining pressure: pore pressure tests. AAPG Bulletin, Vol. 47, No. 5, p. 717-755

Heck et al., 2004. Overview of the petroleum geology of the North Dakota Williston basin. http://www.nd.gov.ndgs/Resources/WBPetroleum H.htm. Accessed 9-03-2009.

Hobbs et al., 1976. An Outline of Structural Geology, Wiley, 571 p.

Jarvie, 2001. Williston Basin petroleum systems: Inferences from oil geochemistry and geology. The Mountain Geologists, Vol. 38, p. 19-41.

Jump, C., 2009. "Our First 100 Horizontals: A Summary of Marathon's Success in the Williston Basin Bakken Shale Play”: Geology Colloquium, April 2, 2009, West Virginia University, Morgantown, West Virginia. 
LeFever, 2007. Lithofacies of the Middle Bakken Member, North Dakota: North Dakota Geological Survey, Geologic Investigations No. 45, sheets 1-6.

LeFever, 2008. Bakken Formation Map Series. North Dakota Geological Survey, Geologic Investigations No.59, sheets 1-5.

LeFever and Helms, 2006. Bakken Formation Reserve Estimates: North Dakota Geological Survey white paper, North Dakota Geological Survey, Bismarck, ND, March 2008, 6 p.

LeFever et al., 1991. Petroleum potential of the middle member, Bakken Formation, Williston Basin. In Christopher \&Haidle (eds.) Sixth International Williston Basin Symposium, Sask. Geol. Soc., Spec. ubl. No 11, pp. 74-94.

Marquez and Mountjoy, 1996. Microfractures Due to Overpressures Caused by Thermal Cracking in WellSealed Upper Devonian Reservoirs: Deep Alberta Basin. AAPG Bulletin, Vol. 80, No.4 p. 570-588.

Meissner, 1978. Petroleum Geology of the Bakken Formation Williston Basin, North Dakota and Montana. In The Economic Geology of the Williston Basin: Montana, North Dakota, South Dakota, Saskatchewan, Manitoba, 1978 Williston Basin Symposium, Mont. Geol. Soc., Billings, pp $207-227$.

Meissner and Banks, 2000. Computer simulation of hydrocarbon generation, migration, and accumulation under hydrodynamic conditions - examples from the Williston and San Juan Basins, USA: AAPG Search and Discovery Article \# 40179

Nordeng, 2009. The Bakken petroleum system: An example of a continuous petroleum accumulation. North Dakota Department of Mineral resources Newsletter, Vol. 36, No. 1, p. 19-22.

Osadetz et al., 1992. Oil families and their source rock in Canadian Williston basin, (southeast Saskatchewan and southwestern Manitoba). Bulletin of Canadian Petroleum Geology, Vol. 40, p. 254-273.

Pitman et al., 2001. Diagenesis and Fracture Development in the Bakken Formation, Williston Basin: Implication for Reservoir Quality in the Middle Member: USGS Professional Paper 1653.

Price, 2000. Origins and Characteristics of the Basin-Centered Continuous Reservoir Unconventional Oil-Resource Base of the Bakken Source System, Williston Basin: Unpublished manuscript. $281 \mathrm{p}$.

Price and LeFever, 1994. Dysfunctionalism in the Williston basin: the mid-Madison/Bakken petroleum system: Bulletin of Canadian Petroleum Geology, Vol. 42, No. 2, p. 187-218

Price and Stolper, 2000. Evidence and Causees of Super-Lithostatic Fracturing, In Price, L.C., 2000, Origins and Characteristics of the Basin-Centered Continuous Reservoir Unconventional Oil-Resource Base of the Bakken Source System, Williston Basin: Section 6.8., Unpublished manuscript, p. $108-130$.

Richards, 1989. Upper Kaskaskia sequence - uppermost Devonian and lower Carboniferous, in Ricketts, ed., Western Canadian sedimentary basin, a case history. Calgary, Alberta, Canadian Society of Petroleum Geologists, p. 165-201.

Seewald, 2003. Organic-inorganic interactions in petroleum-producing sedimentary basins: Nature, Vol. 426, 20 Nov 2003, p. 327-333. 
Smith and Bustin, 1995. Sedimentology of the Late Devonian and Early Mississippian Bakken Formation, Williston Basin. In Hunter \& Schalla (eds.), $7^{\text {th }}$ International Williston Basin Symposium, Mont. Geol. Soc., Guidebook p. 103-114.

Smith and Bustin, 2000. Late Devonian and Early Mississippian Bakken and Exshaw Black Shale Source Rocks, Western Canada sedimentary Basin: A Sequence Stratigraphic Interpretation. AAPG Bulletin, Vol. 84, No.7 (July 2000), p. $940-960$.

Thomas, 1974. Lineament-Block Tectonics: Williston-Blood Creek Basin. AAPG Bulletin Vol. 58, No. 7 p.1305-1322.

Williams, 1974. Characterization of oil types in Williston Basin: AAPG Bulletin, Vol. 58, p. 1243-1252.

Yangus and Dravis, 1985. Blue fluorescent dye technique for recognition of microporosity in sedimentary rocks. Journal of Sedimentary Petrology, Vol. 55, No. 4, p. 600-602.

Zeszotarski et al., 2004. Imaging and mechanical property measurements of kerogen via nanoindentation. Geochemica et Cosmochimica Acta, Vol. 68, Issue 20, p. 4113-4119. 